\title{
Principles and Applications of Dual-Polarization Weather Radar. Part II: Warm- and Cold-Season Applications
}

\author{
MATTHEW R. KUMJIAN \\ Advanced Study Program, National Center for Atmospheric Research*, Boulder, Colorado
}

(Manuscript received 22 April 2013; review completed 7 August 2013)

\begin{abstract}
In this second part of the series, an overview of applications of polarimetric radar observations is given. This includes a summary of improvements to data quality, and interpretation of signatures and output of algorithms for observations made in warm- and cold-season precipitation. Examples of operational products include hydrometeor classification, hail detection and sizing, and quantitative precipitation estimation. Signatures reviewed include those found in severe convective storms and supercells such as differential reflectivity $\left(Z_{\mathrm{DR}}\right)$ columns, $Z_{\mathrm{DR}}$ arcs, and tornadic debris. The melting layer bright band, snow crystal identification and growth regions, and transition of precipitation type in cold-season storms also are discussed. The emphasis is on the current state of our knowledge, as well as ongoing and future research topics that offer promising benefits to operational meteorology.
\end{abstract}

\section{Introduction}

In Part I of this series (Kumjian 2013a), an overview and description of the polarimetric radar variables is given. These include reflectivity factor at horizontal polarization $\left(Z_{H}\right)$, differential reflectivity $\left(Z_{\mathrm{DR}}\right)$, differential propagation phase shift $\left(\Phi_{\mathrm{DP}}\right)$ and specific differential phase $\left(K_{\mathrm{DP}}\right)$, and the co-polar correlation coefficient $\left(C C\right.$ or $\left.\rho_{\text {hv }}\right)$. In this paper, a review of important applications of polarimetric radar data is provided, along with future avenues of research. The applications are broadly categorized into "warm season" and "cold season" events, though these are merely organizational, as there is considerable overlap with many of the applications presented herein.

\section{Improvements to radar data quality}

One of the benefits of polarimetric radar measurements is the possible improvements to radar data quality. Data from low-level scans with polarimetric Weather Surveillance Radar-1988 Doppler (WSR88D) radars are collected at an azimuthal spacing of $0.5^{\circ}$, in what is known as "super resolution." However, the polarimetric variables are displayed after (i) being recombined to $1^{\circ}$ azimuthal spacing and (ii) smoothed during the so-called "pre-processing" stage. In this stage, the smoothed $\Phi_{\mathrm{DP}}$ is used to compute $K_{\mathrm{DP}}$ as well as to correct for attenuation of and differential attenuation of $Z_{\mathrm{DR}}$ [see Kumjian (2013b), hereafter Part III, for a more thorough discussion of attenuation]. Though the base moments of $Z_{H}$, Doppler velocity, and Doppler spectrum width are displayed with $0.5^{\circ}$ spacing, recombined, smoothed, and attenuation-corrected $1^{\circ} Z_{H}$ is used for the different automated algorithms discussed in the following sections.

The polarimetric data are used to help improve clutter identification. In the first step of clutter filtering, the clutter mitigation decision algorithm identifies radar gates as contaminated by clutter. In the newest version, dual-polarization information is used to better identify clutter. Specifically, texture fields (i.e., the standard deviation) of $Z_{\mathrm{DR}}$ and $\Phi_{\mathrm{DP}}$ are used. Higher standard deviations of $Z_{\mathrm{DR}}$ and $\Phi_{\mathrm{DP}}$ are more likely associated with clutter, whereas lower standard deviations are more characteristic of weather echoes. In addition to improved clutter detection, polarimetric radar variables are used to improve detection of nonmeteorological echoes and improve rainfall estimation. These improvements are detailed in the fol-

\footnotetext{
*The National Center for Atmospheric Research is sponsored by the National Science Foundation. Corresponding author address: Dr. Matthew R. Kumjian, NCAR, P.O. Box 3000, Boulder, CO 80307 E-mail: kumjian@psu.edu
} 
lowing section. Data quality problems are discussed in more detail in Part III of this series.

\section{Warm-season applications}

\section{a. Hydrometeor classification}

Each of the polarimetric radar variables discussed in Part I provides important information that allows meteorologists to infer the reflectivity-dominant types and sizes of particles within the radar sampling volume. Motivated by an attempt to distill the informative content of each variable to a single hydrometeor classification product, Straka and Zrnić (1993) developed a preliminary "fuzzy-logic" based scheme that takes the measured radar variables and assigns "fuzzy" probabilities for certain hydrometeor types for a given range of values. Such methods were refined and expanded by Höller et al. (1994), Vivekanandan et al. (1999), Straka et al. (2000), Liu and Chadrasekar (2000), Lim et al. (2005), Ryzhkov et al. (2005a), Dolan and Rutledge (2009), and Dolan et al. (2013). Currently, the upgraded WSR-88D radars are using the hydrometeor classification algorithm (HCA) described in Park et al. (2009). The HCA classifies radar echoes into one of 10 categories: biological scatterers, ground clutter, light/moderate rain, heavy rain, "big drops," rain/hail mixture, dry snow, wet snow, ice crystals, and graupel. Note that although the radar sampling volume often contains a mixture of hydrometeor types, only the rain/hail mixture category captures this sense of a mixture. Though it appears to work well in warm-season storms, its performance in winter weather requires improvement (e.g., Elmore 2011). Such work is underway at the National Severe Storms Laboratory (Schuur et al. 2012) and at Colorado State University (Thompson et al. 2014).

The basic idea behind hydrometeor classification is that each hydrometeor type has its own range of values for each of the measured polarimetric radar variables [see Part I and the Warning Decision Training Branch (WDTB) training aids]. Each radar range gate has a measured $Z_{H}, Z_{\mathrm{DR}}, K_{\mathrm{DP}}$, and $\rho_{\mathrm{hv}}(C C)$. (Additionally, several HCAs use texture parameters, which include the standard deviations of the measured $\Phi_{\mathrm{DP}}$ and $Z_{\mathrm{DR}}$.) The likelihood that a given hydrometeor class falls within the observed range of values of each polarimetric radar variable is given by so-called membership functions. These membership functions assign a likelihood value ( 0 to 1$)$ that a particular hydrometeor class falls within a range of values of each polarimetric variable (Fig. 1). For example, it is highly unlikely that measured $\rho_{\mathrm{hv}}(C C)$ values of 0.4 correspond to rain; instead, it is far more likely that biological scatterers or ground clutter causes such values. The shape of the membership function is given, for example, by trapezoids (e.g., Park et al. 2009) or beta functions (e.g., Liu and Chandrasekar 2000; Lim et al. 2005). The trapezoidal functions allow for asymmetric shapes, which better characterize certain distributions (e.g., ground clutter and $\rho_{\mathrm{hv}}$; Zrnić et al. 2006). By aggregating the likelihood value of each class for each variable, the algorithm determines the most likely dominant hydrometeor class. The version used operationally with the WSR-88D radar network accounts for data quality problems by weighting the membership functions and flagging areas of questionable data quality (see Park et al. 2009). In addition, the melting layer detection algorithm (MLDA, see section 4a) is used to delineate a subset of possible classes for gates above and below the melting layer top and bottom, respectively.

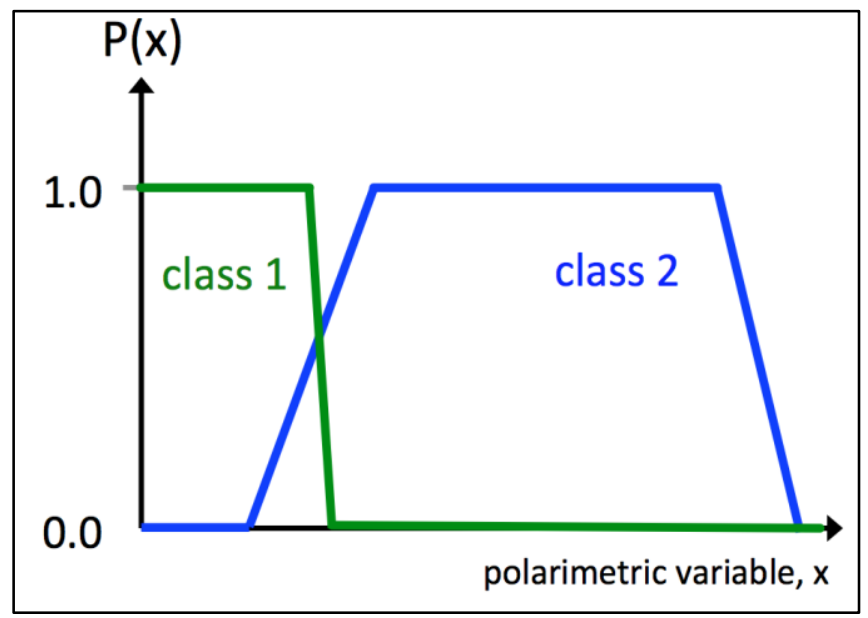

Figure 1. Schematic illustrating the concept of membership functions for two hydrometeor classes (blue and green trapezoids) as a function of some polarimetric variable, $x$. The ordinate axis shows likelihood value $P(x)$ of that class alone being present for a given value of the polarimetric radar variable, $x$. Click image for an external version; this applies to all figures hereafter.

An example of output from the HCA is shown in Fig. 2. In the supercell storm to the east of the radar, the algorithm provides output based on the informative content from all polarimetric variables at each range gate and shows several features of interest, including hail/rain in the main precipitation core (red color) surrounded by heavy rain (dark green color), as well as "big drops" along the inflow flank of the echo. The "big drop" region is consistent with the $Z_{\mathrm{DR}}$ arc 


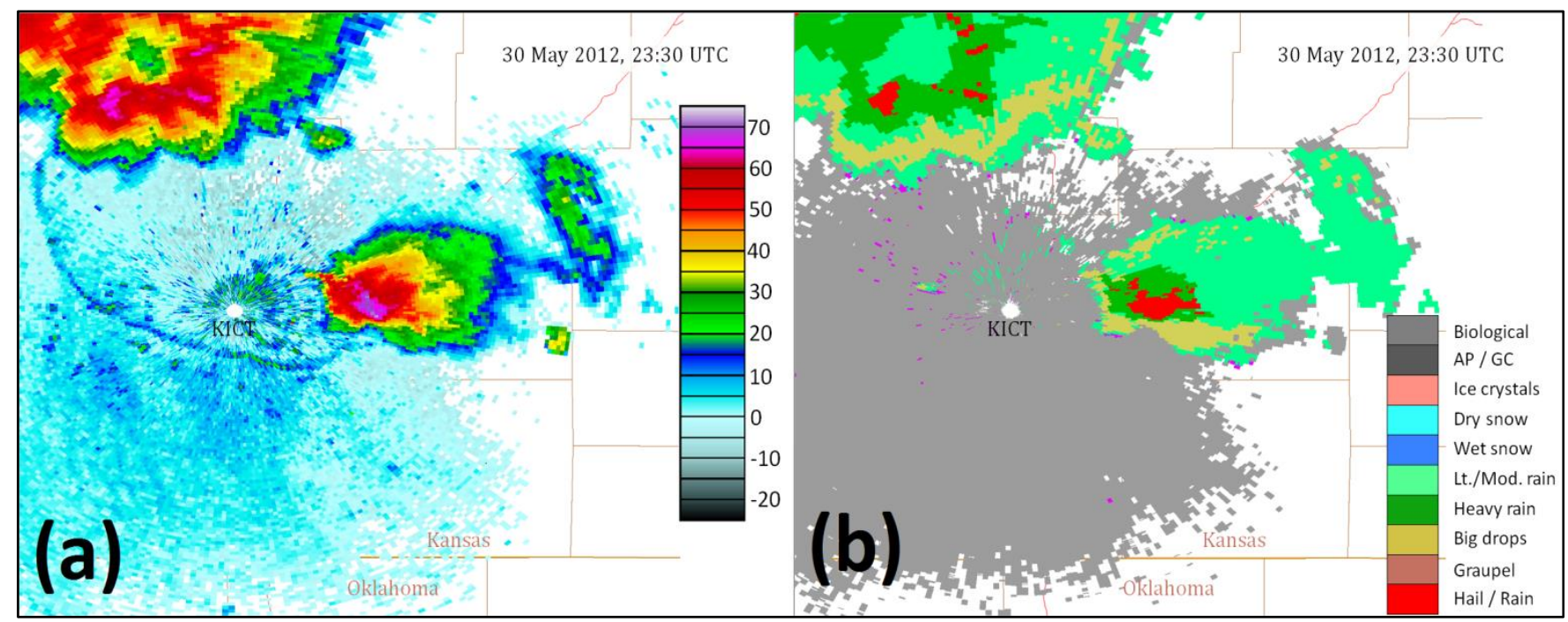

Figure 2. (a) Base reflectivity factor $\left(Z_{H}\right)$ from 2330 UTC 30 May 2012, as observed by the polarimetric WSR-88D radar near Wichita, KS (KICT). (b) Hydrometeor classification output.

signature typical of supercell storms (see section $3 \mathrm{e}$ ). Hail up to $4.4 \mathrm{~cm}$ ( $1.75 \mathrm{in}$ ) in diameter was observed at the surface with this storm. Outside of the precipitation regions, the light-reflectivity regions surrounding the radar (including the "fine line" marking the outflow boundary) are classified as biological scatterers. Future implementations of the HCA will include a hail size discrimination algorithm, described in the next section.

Poor radar data quality and/or biases in $Z_{\mathrm{DR}}$ can be detrimental to the HCA. For example, Fig. 3 shows a cluster of storms near Amarillo, Texas, in which nonuniform beamfilling (see Part III of this series) causes a radial reduction of $C C$ (Fig. 3b). Because $C C$ values decrease below what is expected for meteorological targets, the $K_{\mathrm{DP}}$ field shows censored (i.e., blank) data (Fig. 3c), and the HCA output erroneously produces a radial stripe of nonmeteorological scatterers (Fig. 3d). In addition, in-situ observations to verify the inferred hydrometeor structure aloft generally are lacking. Work is ongoing to develop an HCA that projects the hydrometeor type to the ground (Schuur et al. 2012), where verification using ground reports is more feasible (e.g., Ortega et al. 2009, 2012; Flamig et al. 2013).

\section{b. Hail detection and sizing}

As mentioned above, polarimetric radar data may be used to identify the location of hail in convective storms. Since the 1980s (Aydin et al. 1986; Bringi et al. 1986; Wakimoto and Bringi 1988), it has been known that large hail can be identified in regions of large $Z_{H}$, near-zero $Z_{\mathrm{DR}}$, and reduced $C C$ or $\rho_{\mathrm{hv}}$ (Fig. 4 ; see also Part I). Heinselman and Ryzhkov (2006) validated the ability of polarimetric radar measurements to correctly identify regions of hail and found a $100 \%$ probability of detection and a smaller false alarm ratio than conventional methods based on $Z_{H}$ alone. Though such methods easily identify large hail, recall that smaller melting hailstones tend to have $Z_{\mathrm{DR}}$ values comparable to rain (see Part I). Thus, for identifying regions of smaller hail, large $Z_{H}$ and reduced $C C\left(\rho_{\mathrm{hv}}\right)$ are the best indicators. Note that the near-zero $Z_{\mathrm{DR}}$ signature for large hail usually is not present for radars operating at $\mathrm{C}$ band (e.g., Kumjian and Ryzhkov 2008; Anderson et al. 2011; Ryzhkov et al. 2013a), owing to resonance scattering effects by larger $(5-6 \mathrm{~mm})$ raindrops and smaller melting hailstones, which tend to overwhelm the backscattered signal.

In addition to hail detection, current work is exploring the possibility of using polarimetric and thermodynamic information to discriminate between small, large, and giant hail (e.g., Kumjian et al. 2010a; Picca and Ryzhkov 2012; Ryzhkov et al. 2013b). The method is based on exploiting the differences in melting characteristics of small and large hailstones (e.g., Ryzhkov et al. 2009, 2013a,b). Preliminary results are promising (e.g., Kumjian et al. 2012a; Ortega et al. 2012). Smaller stones that retain larger mass fractions of water tend to have higher $Z_{\mathrm{DR}}$ than larger stones, which shed much of their liquid melt water (e.g., Rasmussen and Heymsfield 1987). Detection of giant hail aloft may be possible by 


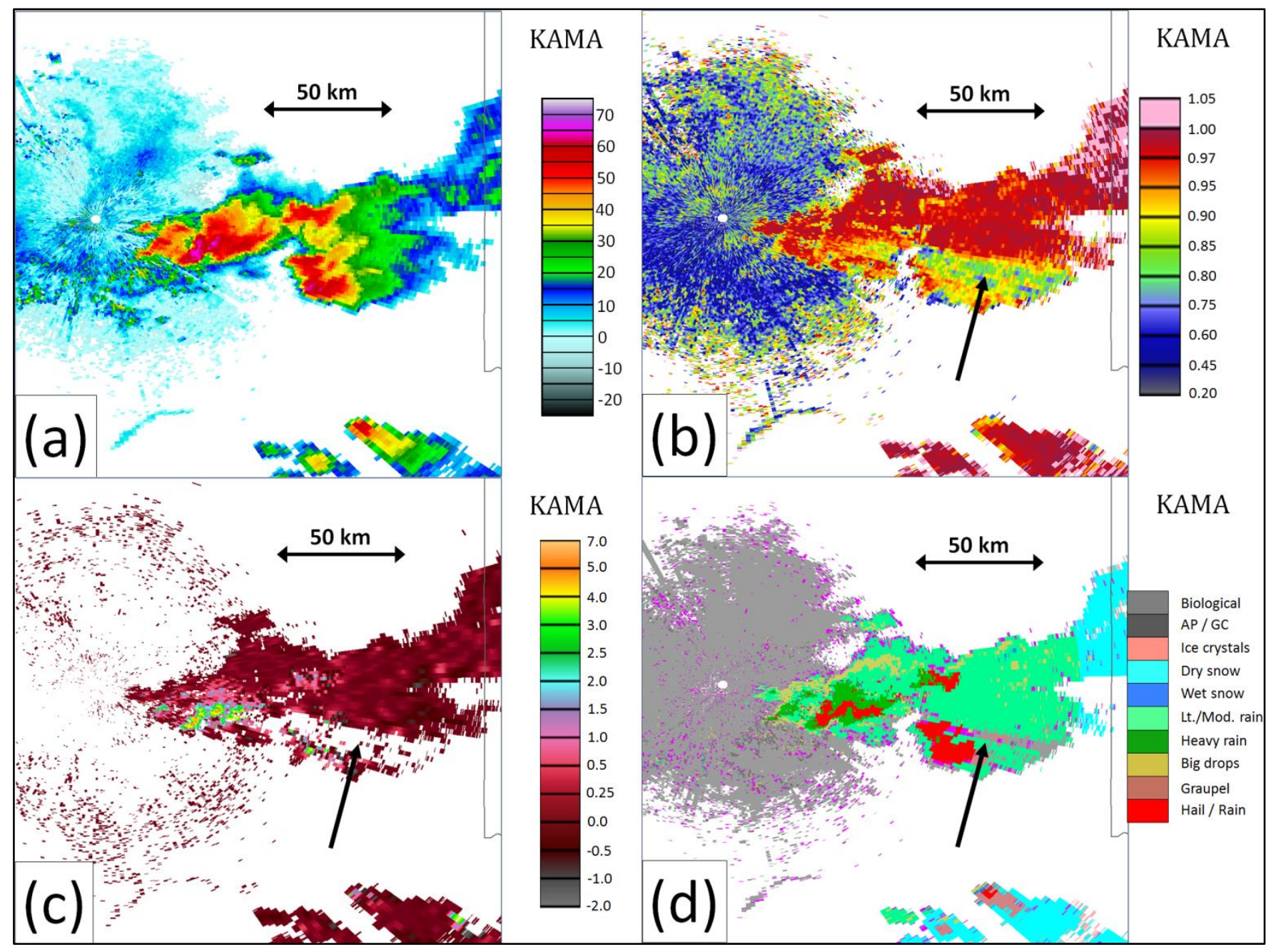

Figure 3. Data from the polarimetric WSR-88D near Amarillo, TX, (KAMA) at 0010 UTC 1 May 2012, taken at $0.5^{\circ}$ elevation. Fields shown are (a) $Z_{H}$, (b) $\rho_{\mathrm{hv}}$ or $C C$ (c) $K_{\mathrm{DP}}$, and (d) HCA. The black arrow indicates a region affected by nonuniform beam filling that negatively affects the estimate of $K_{\mathrm{DP}}$ and causes erroneous classification.

identifying regions of ongoing wet hail growth in the -10 to $-20^{\circ} \mathrm{C}$ region of clouds, in which giant wet hailstones produce anomalously low $\rho_{\mathrm{hv}}$ or $C C$ (e.g., Picca and Ryzhkov 2012). Note that $Z_{H}$ alone does not appear to be a useful discriminator of maximum hail size (e.g., Kumjian et al. 2010a; Blair et al. 2011). In fact, there is some evidence that the highest observed $Z_{H}$ values may correspond to high concentrations of small-to-medium-sized hail, whereas the largest hail corresponds to more modest $Z_{H}$ values located along $Z_{H}$ gradients in the vicinity of the updraft (Blair et al. 2011, 2012).

\section{c. Quantitative precipitation estimation}

Accurate quantitative precipitation estimation (QPE) always has been a primary goal of radar meteorologists and hydrologists. Conventional single- polarization radars have been used to estimate rainfall by selecting one of literally hundreds of possible $Z-R$ relations; that is, relations between the observed radar reflectivity factor and the rainfall rate. The natural variability of drop size distributions (DSDs) depends on geographic location, season, and the characteristics of the precipitating system, among other factors. Such a wide variety of DSDs means that it is impossible for a single $Z-R$ relation to accurately quantify rainfall in all locations and all seasons (e.g., Battan 1973; Doviak and Zrnić 1993).

Dual-polarization radar observations can improve rainfall estimation because they provide some additional information regarding the DSD. For example, $Z_{\mathrm{DR}}$ is related to the characteristic drop size in the DSD, as explained in Part I. Additionally, whereas $Z_{H}$ alone cannot be used to distinguish 

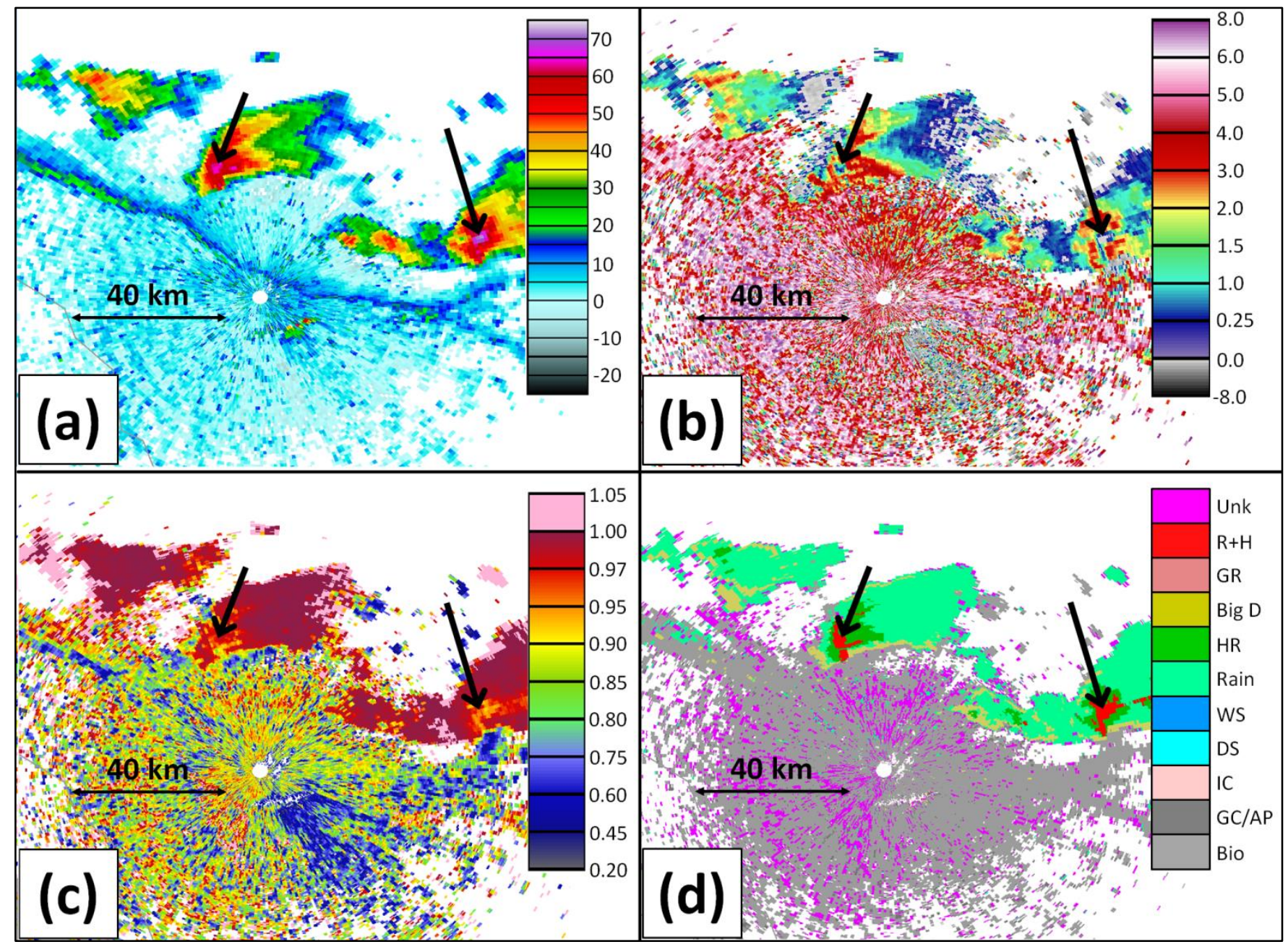

Figure 4. PPI display of (a) $Z_{H}$, (b) $Z_{\mathrm{DR}}$, (c) $\rho_{\mathrm{hv}}$ or $C C$, and (d) HCA from the polarimetric WSR-88D radar near Laughlin Air Force Base, TX, (KDFX). Data are taken from the $0.5^{\circ}$ elevation angle at 2209 UTC 31 March 2013. Note the near-zero $Z_{\mathrm{DR}}$ and reduced $C C$ ( $\rho_{\text {hv }}$ ) within the high- $Z_{H}$ core of the storm, annotated by arrows in the above plots. Also note the HCA classification of "Rain and Hail" (red) for these areas. Hail to the size of tennis balls was reported in these storms.

between rain and hail, polarimetric data can be used to identify regions of rain and hail, and even to estimate the liquid water content of rain when mixed with hail. In fact, Ryzhkov et al. (2005a) found that dualpolarization QPE made improvements upon conventional QPE within $90 \mathrm{~km}$ of the radar. These improvements were primarily attributable to better characterization of the DSD and areas of hail contamination. Further, improved data quality control is possible with polarimetric data, owing to the ability to correct for attenuation and partial beam blockage (Zrnić and Ryzhkov 1999; Ryzhkov et al. 2005a). Specifically, rainfall estimation using $K_{\mathrm{DP}}$ has shown to be useful in some situations (e.g., in suspected cases of hail contamination and in partial beam blockage).

The current dual-polarization WSR-88D radar algorithm for QPE makes use of three rainfall rate equations that were empirically derived from central Oklahoma events. The three equations (see Ryzhkov et al. 2005a; Giangrande and Ryzhkov 2008) are expressions of (i) rainfall rate as a function of $Z_{H}$, or $R\left(Z_{H}\right)$; (ii) rainfall rate as a function of $Z_{H}$ and $Z_{\mathrm{DR}}$, or $R\left(Z_{H}\right.$, $Z_{\mathrm{DR}}$ ); and (iii) rainfall rate as a function of $K_{\mathrm{DP}}$, or $\mathrm{R}\left(K_{\mathrm{DP}}\right)$. This is in contrast to the conventional (or legacy) WSR-88D QPE algorithm, in which one of five $R\left(Z_{H}\right)$ relations could be selected.

In the new polarimetric systems, the choice of the rainfall rate equation is based on smoothed output of the HCA and the MLDA. For example, the $R\left(K_{\mathrm{DP}}\right)$ relation is used when the mixture of rain and hail is designated, whereas the rainfall rate $R=0$ is used when biological scatterers are detected. On the other hand, when dry snow is detected above the melting 
layer top, the QPE algorithm uses the $R\left(Z_{H}\right)$ relation modified by a multiplicative factor.

Currently, the $R\left(Z_{H}\right)$ relation is only used for range gates within and above the melting layer and/or in regions designated as ice hydrometeors (graupel, rain/hail above the melting layer top, dry snow, wet snow, and ice crystals). The relation has different multiplicative factors for each scenario, also derived empirically. This can lead to discontinuities in the rainfall accumulation maps within or near the melting layer, particularly for accumulations over longer durations. Unlike the $R\left(Z_{H}\right)$ relation, the $R\left(Z_{H}, Z_{\mathrm{DR}}\right)$ equation can capture some of the variability of the DSD through its use of $Z_{\mathrm{DR}}$. Thus, it is used when the HCA designates range gates as any of the pure rain categories (light/moderate rain, heavy rain, and big drops). However, it is quite sensitive to $Z_{\mathrm{DR}}$ calibration, requiring an accuracy of $0.1-0.2 \mathrm{~dB}$ to maintain acceptably small errors in rainfall intensity estimates. The $R\left(K_{\mathrm{DP}}\right)$ relation is most advantageous in regions of partial beam blockage and when the HCA classifies hail mixed with rain. In addition, $R\left(K_{\mathrm{DP}}\right)$ is the least sensitive to variability of the DSD. However, estimates of $K_{\mathrm{DP}}$ can be noisy, especially in regions of light rain and low $C C$.

After choosing the appropriate rainfall rate equation, the polarimetric QPE system then builds a variety of QPE products. The resulting rainfall products implemented with the dual-polarization WSR-88D radars are instantaneous rainfall rate, accumulation products, and difference products. The digital precipitation rate provides the instantaneous precipitation rate at each volume scan based on the rainfall rate equations described above. The accumulation products include one-hour accumulations, storm-total accumulations, and accumulations over user-defined durations that can range from $15 \mathrm{~min}$ to 24 h. Finally, the difference products show the difference between the dual-polarization precipitation accumulation estimates and the legacy estimates for 1$\mathrm{h}$ and storm-total accumulations.

The dual-polarization QPE products do have advantages over legacy products. By incorporating information from the HCA, dual-polarization QPE products prevent non-meteorological scatterers from contributing to rainfall accumulations. The polarimetric products are better able to capture DSD variability and are less likely to be strongly biased by the presence of hail. Additionally, compared to the legacy precipitation products, an instantaneous digital precipitation rate product is available after every volume scan.

However, the rainfall rate equations were derived empirically in Oklahoma. Thus, "tuning" may be required for other regions. Because of the multiplicative factors used with the $R\left(Z_{H}\right)$ relation within and above the melting layer, sharp discontinuities may appear in rainfall accumulation products, as described above. Also, invalid classifications by the HCA can lead to errors in the dual-polarization QPE products (e.g., nonuniform beamfilling may cause reduced $C C$ pixels that are classified as nonmeteorological, causing $R$ to be set to zero, when in fact precipitation is occurring at those locations; cf. Fig. 3).

The dual-polarization WSR-88D QPE algorithm is a work in progress. In future builds of the WSR-88D signal processing software, the rainfall relation used when dry snow is detected will be a function of $Z_{H}$ as well as the environmental temperature (A. Ryzhkov 2013, personal communication). Within the melting layer, rainfall rate will be determined as a linear interpolation between the rainfall rate in pure rain and the temperature-dependent rainfall rate determined in pure snow. Such a technique mitigates the appearance of artificial discontinuities in rainfall accumulation products.

Unfortunately, there is no perfect method for QPE in all situations. However, ongoing work and the increasing availability of radar data over surface gauge networks will lead to further improvements in the techniques and refinements of rainfall relations. What is unequivocal is the potential for improvements realized by dual-polarization-based QPE in many (but not all) situations.

\section{d. $Z_{\mathrm{DR}}$ columns}

One of the most notable polarimetric signatures in many convective storms is a columnar region of enhanced $Z_{\mathrm{DR}}$ that extends above the environmental $0^{\circ} \mathrm{C}$ level. Known as " $Z_{\mathrm{DR}}$ columns," these signatures mark the location of convective updrafts as supercooled drops and wet ice particles are lofted to subfreezing temperatures. Since the early observations of $Z_{\mathrm{DR}}$ columns (e.g., Hall et al. 1984; Caylor and Illingworth 1987; Illingworth et al. 1987; Tuttle et al. 1989), such features have been widely documented in the scientific literature (e.g., Meischner et al. 1991; Bringi et al. 1991, 1997; Herzegh and Jameson 1992; Conway and Zrnić 1993; Höller et al. 1994; Brandes et 
al. 1995; Jameson et al. 1996; Hubbert et al. 1998; Smith et al. 1999; Kennedy et al. 2001; Loney et al. 2002; Ryzhkov et al. 2005b; Scharfenberg et al. 2005; Kumjian and Ryzhkov 2008; Kumjian et al. 2010b; Payne et al. 2010; Rowe et al. 2011). These studies have established that the $Z_{\mathrm{DR}}$ column is located within (in ordinary convective storms) or on the periphery of (in supercells) the updraft maximum. In-situ measurements made during aircraft penetrations have confirmed inferences about hydrometeor type based on the polarimetric observations: that $Z_{\mathrm{DR}}$ columns comprise large drops and wet graupel and hail (e.g., Bringi et al. 1991; Brandes et al. 1995; Loney et al. 2002; Schlatter 2003).

Though $Z_{\mathrm{DR}}$ columns are best identified in vertical cross-section or range height indicator (RHI) scans [e.g., cross sections can be constructed using the fourdimensional storm investigator tool in the Advanced Weather Interactive Processing System (AWIPS)], they can be inferred from plan position indicator (PPI) scans by examining higher-level tilts, especially those in which most of the echo is above the environmental $0^{\circ} \mathrm{C}$ level. The $Z_{\mathrm{DR}}$ column will appear as a localized area of positive $Z_{\mathrm{DR}}$, typically upshear of the rest of the echo (Fig. 5). Note that enhanced $Z_{\mathrm{DR}}$ often extends towards the ground as well, typically offset from the largest $Z_{H}$ values when viewed in low-level PPI scans. The inferred sparse concentration of large drops implies ongoing drop sorting by the updraft aloft, as pointed out in Bringi et al. (1997), Bringi and Chandrasekar (2001), Kollias et al. (2001), Ryzhkov et al. (2005b), and Kumjian and Ryzhkov (2008, 2012).

Recent work has confirmed that $Z_{\mathrm{DR}}$ column evolution is linked to the storm's behavior. Namely, increases in the $Z_{\mathrm{DR}}$ column height or areal extent precede an increase in the low-level reflectivity by 10 15 minutes (e.g., Picca et al. 2010). In other words, it seems as if an increase in updraft strength (manifested as an increase in the $Z_{\mathrm{DR}}$ column height and/or extent) produces an increase in surface precipitation rate and/or hail intensity after 10-15 minutes. Such information can be useful in nowcasting the strength of cells and monitoring convective trends. In more theoretical work, Kumjian et al. (2012b) have demonstrated a link between increased updraft strength and taller $Z_{\mathrm{DR}}$ columns through two mechanisms: (i) faster transport of liquid particles to subfreezing temperatures and (ii) more rapid cooling of liquid particles that delays the nucleation and thus freezing to higher altitudes. Future work will investigate the possibility of using $Z_{\mathrm{DR}}$ column height to

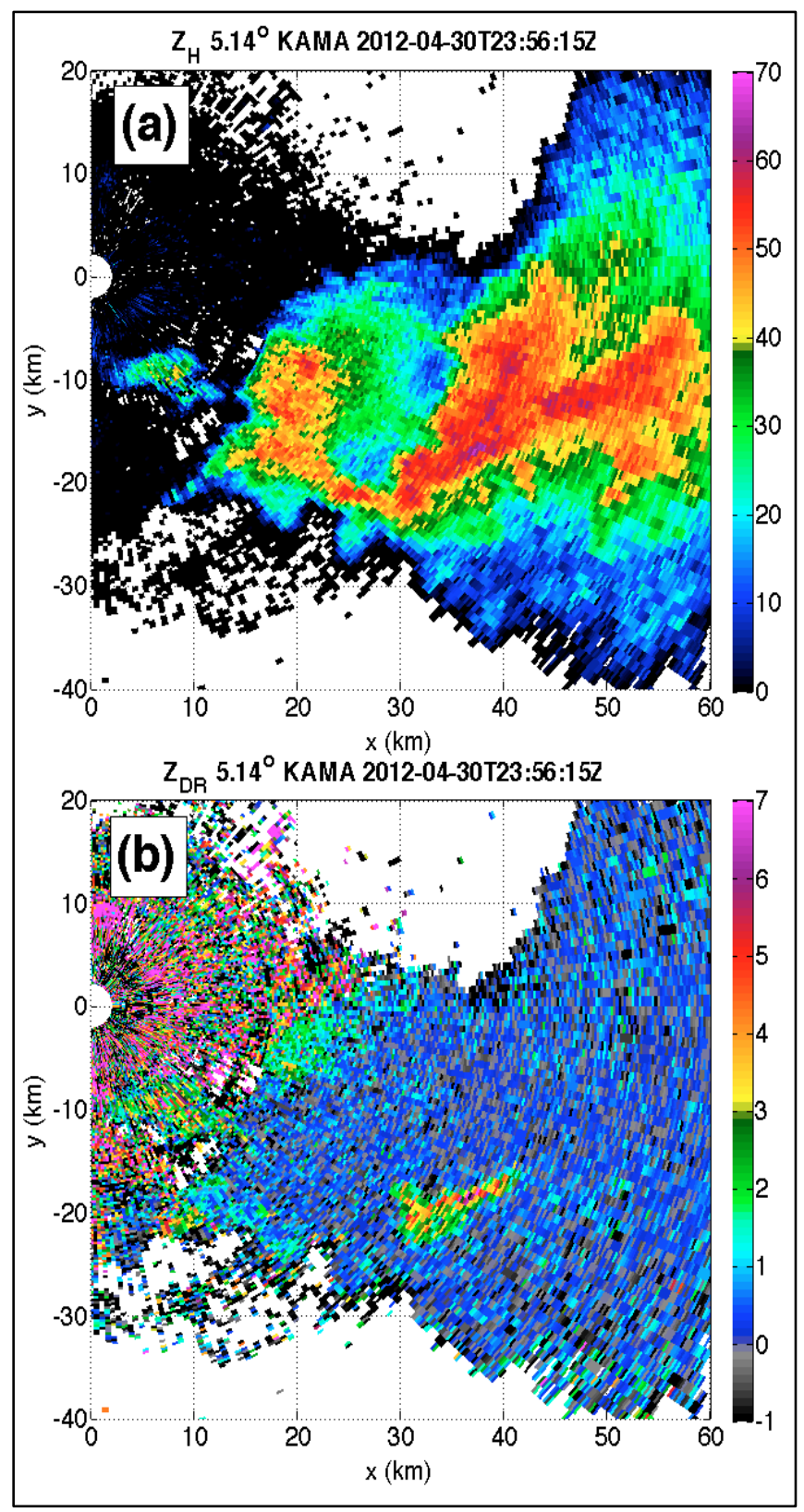

Figure 5. Display of (a) $Z_{H}$ and (b) $Z_{\mathrm{DR}}$ from the polarimetric WSR-88D radar near Amarillo, TX (KAMA). Data collected at 2358 UTC 30 April 2012, from $5.1^{\circ}$ elevation. Note that these are level-II data, used because of the availability of higher elevation angle scans. The height of the centroid of the $Z_{\mathrm{DR}}$ column is about $3.7 \mathrm{~km}$ AGL.

quantify the updraft intensity, as well as to evaluate the reliability of changes in $Z_{\mathrm{DR}}$ column height as a metric for changes in updraft intensity.

In addition to the height of $Z_{\mathrm{DR}}$ columns, its shape and size (areal extent) may be important sources of information as well. For example, in storms with midlevel rotation, the shape of the $Z_{\mathrm{DR}}$ column is distorted into a ring or half-ring shape encircling the 
maximum in vertical vorticity, called a midlevel " $Z_{\mathrm{DR}}$ ring" (e.g., Kumjian and Ryzhkov 2008; Kumjian et al. 2010b; Payne et al. 2010; Palmer et al. 2011; Heymsfield et al. 2013; Snyder et al. 2013). Because broad updrafts are more conducive for the growth of large hail (e.g., Nelson 1983; Conway and Zrnić 1993; Picca and Ryzhkov 2012, among others), larger areal extents of $Z_{\mathrm{DR}}$ columns (when viewed in PPI displays) may indicate conditions more favorable for the development of large hail. For example, the broad $Z_{\mathrm{DR}}$ column in Fig. 5 was observed shortly before the storm produced hail larger than baseballs.

\section{e. $Z_{\mathrm{DR}}$ arc signature}

Kumjian and Ryzhkov (2008) identified several polarimetric radar signatures that are seemingly characteristic of supercell storms. One such signature is the " $Z_{\mathrm{DR}}$ arc." The $Z_{\mathrm{DR}}$ arc is observed as a low-level $\left(<2 \mathrm{~km}\right.$ AGL), arc-shaped region of high $Z_{\mathrm{DR}}(>3 \mathrm{~dB})$ located along the gradient of $Z_{H}$ along the inflow side of the forward flank of supercell storms (Fig. 6). It is hypothesized to appear as a result of strong size sorting in the presence of strong veering wind shear in supercell environments (Kumjian and Ryzhkov 2008, 2009). Specifically, the orientation or alignment of the $Z_{\mathrm{DR}}$ arc is a result of (and positively correlated to) the presence of storm-relative helicity in the storm inflow (Kumjian and Ryzhkov 2009). Subsequent work by Yu et al. (2009), Carey et al. (2010), Jung et al. (2010), and Dawson et al. (2013) support the size-sorting hypothesis.

In some cases, the $Z_{\mathrm{DR}}$ arc appears before the hook echo signature, giving forecasters the ability to identify storms that are transitioning into more severe modes. Though omnipresent in supercell storms, this type of information can be particularly useful in nonsupercell storms in the southeastern United States and/or quasi-linear convective system (QLCS) situations, alerting forecasters to storms that are becoming potentially tornadic. Crowe et al. (2012) and Mahale et al. (2013) have shown the added diagnostic value of the $Z_{\mathrm{DR}}$ arc signature in various nonsupercell cases. In particular, Crowe et al. (2012) focus on the offset in the maxima of $K_{\mathrm{DP}}$ and $Z_{\mathrm{DR}}$ (see also Fig. 6d), suggesting that larger offsets (implying larger lowlevel shear) may be more conducive to tornadogenesis.

Kumjian et al. (2010b) and Palmer et al. (2011) show how the $Z_{\mathrm{DR}}$ arc evolution is tied to storm morphology and behavior. In brief, the $Z_{\mathrm{DR}}$ arc tends to extend back into the inflow notch of supercells leading up to the strengthening of the low-level mesocyclone and potential tornadogenesis. After the occlusion of the low-level mesocyclone, the $Z_{\mathrm{DR}}$ arc tends to be "disrupted," and a new arc may form along the forward-flank precipitation echo. Kumjian and Ryzhkov (2008) also found that the $Z_{\mathrm{DR}}$ arc disruption tended to be more persistent in nontornadic storms than tornadic storms, albeit for a small dataset. More investigation is required to determine the reliability of the $Z_{\mathrm{DR}}$ arc signature (or its disruption) as an indicator of a supercell's tornadic potential.

\section{f. Tornadic debris signature}

A familiar example of the utility of polarimetric radar data is the detection of lofted tornadic debris, or the tornadic debris signature (TDS; Fig. 7). Ryzhkov et al. $(2002,2005 \mathrm{~b})$ first documented the signature, which appears as a region of anomalously low $C C$ $\left(\rho_{\text {hv }}\right)$ collocated with a Doppler velocity vortex signature. Since the initial pioneering work by A. Ryzhkov and collaborators at the National Severe Storms Laboratory, the TDS has been documented in the published literature across the country at various radar wavelengths (e.g., Scharfenberg et al. 2005; Bluestein et al. 2007; Kumjian and Ryzhkov 2008; Snyder et al. 2010, 2013; Kumjian 2011; Palmer et al. 2011; Schultz et al. 2012a,b; Tanamachi et al. 2012; Bodine et al. 2013), as well as in many conference proceedings at American Meteorological Society, National Weather Association, and European Radar meetings.

Often, the TDS also is observed to have reduced (near-zero or even negative) $Z_{\mathrm{DR}}$ and high $Z_{H}$. The reduction in $\rho_{\mathrm{hv}}(C C)$ is attributable to the large variability of shapes of tornadic debris being lofted and tumbling within the radar sampling volume. Tumbling of particles also reduces $Z_{\mathrm{DR}}$, though in some cases precipitation entrained into the tornadic circulation can cause higher $Z_{\mathrm{DR}}$ values closer to what is observed in precipitation (Kumjian and Ryzhkov 2008; Bodine et al. 2011). It is unclear what causes the negative $Z_{\mathrm{DR}}$ values sometimes observed (e.g., Fig. 7), though it indicates some degree of alignment of the debris.

The TDS offers no prognostic value, as it only provides confirmation that a damaging tornado is occurring (or has recently occurred). However, recent research has focused on exploring the operational utility of the signature for possible real-time damage estimation (e.g., Bodine et al. 2013) as well as 


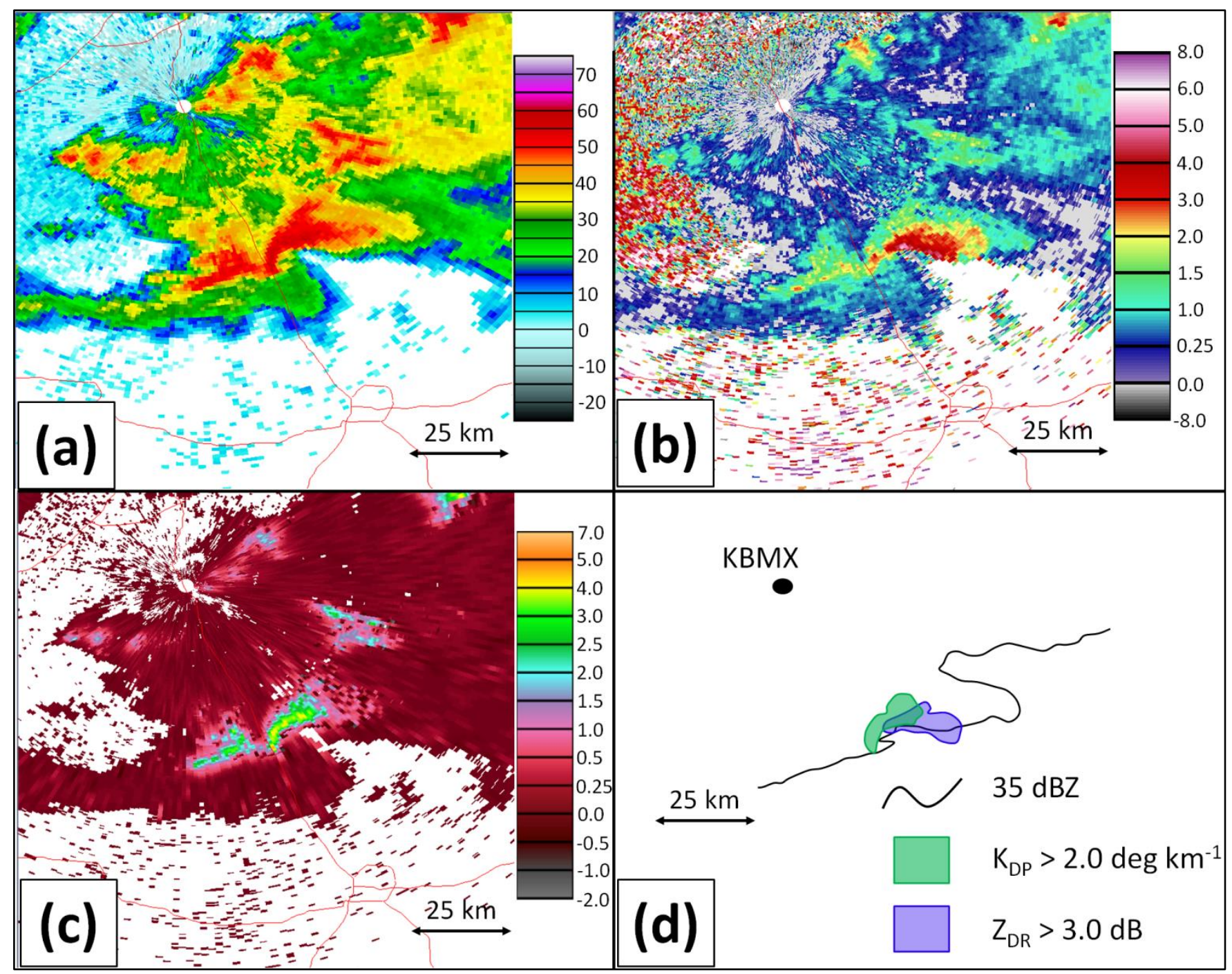

Figure 6. Display of (a) $Z_{H}$, (b) $Z_{\mathrm{DR}}$, and (c) $K_{\mathrm{DP}}$ from 0403 UTC 3 March 2012, as observed by the polarimetric WSR-88D radar near Birmingham, AL (KBMX). Data were collected at $0.5^{\circ}$ elevation. (d) Subjective outlines of the 35-dBZ reflectivity echo (solid black curve), $Z_{\mathrm{DR}}$ arc (royal purple shading), and enhanced $K_{\mathrm{DP}}$ region (green shading) are overlaid to aid the interpretation of the data.

reviewing the practical considerations and caveats of the operational use of such signatures (e.g., Schultz et al. 2012a,b). Though limited in generality by a small sample size and statistical scatter, Bodine et al. (2013) found that stronger tornadoes tend to have TDSs that extended to higher altitudes, as well as have TDSs with lower 10th percentile $\rho_{\mathrm{hv}}(C C)$ values (after thresholding the data such that they must exceed a minimum median value of $Z_{H}$ ). The robustness of this finding will be evaluated in subsequent studies as more cases become available for analysis. In the meantime, the reference for how the TDS fits into the broader context of tornado warning decisions was updated by the WDTB (Warning Decision Training Branch 2013). Now, TDS characteristics are given as training in a quick reference guide to the many tornado strength indicators on radar in the near-storm environment.

\section{g. Other supercell signatures}

In addition to the signature of large hail, $Z_{\mathrm{DR}}$ column, $Z_{\mathrm{DR}}$ arc, and TDS discussed above, several papers have documented other polarimetric signatures that are frequently observed in supercell storms (e.g., Kumjian and Ryzhkov 2008, 2010b; Romine et al. 2008; Tanamachi et al. 2012; Snyder et al. 2013). Figure 8 is a conceptual model of these repetitive signatures at three different levels. At low levels, an area of enhanced $K_{\mathrm{DP}}$ often is observed within the heavy precipitation core of supercells, called the 


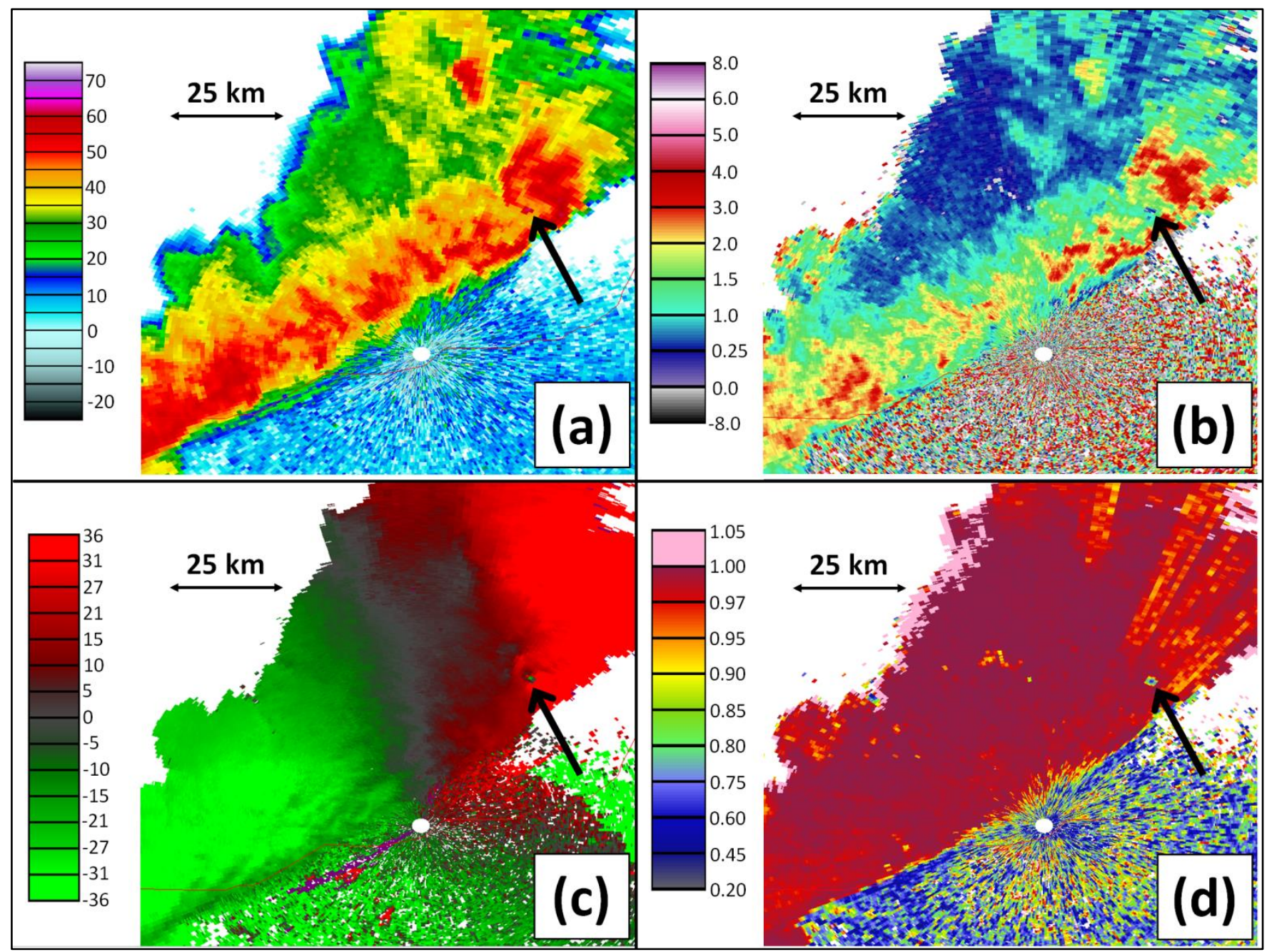

Figure 7. Display of (a) $Z_{H}$, (b) $Z_{\mathrm{DR}}$, (c) Doppler velocity, and (d) $C C$ ( $\rho_{\mathrm{hv}}$ ) from the polarimetric WSR-88D radar in Springfield, MO (KSGF), at 0605 UTC 29 February 2012. Data show a tornadic debris signature, marked by the arrows. Note the tornado was rain-wrapped and occurred at night. The height of the radar beam at the location of the debris signature is approximately $540 \mathrm{~m}$ AGL.

" $K_{\mathrm{DP}}$ foot" (Romine et al. 2008). Though it largely overlaps the $Z_{H}$ core, $K_{\mathrm{DP}}$ is less sensitive to large hail and thus is a better indicator of heavy rain and small melting hail. Thus, the $K_{\mathrm{DP}}$ foot may be a better indicator of the downdraft regions, at least those driven by rain evaporation and melting of hail. However, $K_{\mathrm{DP}}$ estimation is frequently difficult in supercells because such storms often exhibit nonRayleigh scatterers (e.g., large hail) and sharp gradients of $Z_{H}$ and $\Phi_{\mathrm{DP}}$ that lead to nonuniform beam filling (see Part III).

Also observed at low levels is the so-called "inflow signature" (Kumjian and Ryzhkov 2008), which appears as a significant reduction in $\rho_{\mathrm{hv}}(C C)$ in the inflow region of supercells. Typically, $Z_{H}$ is low $(<20 \mathrm{dBZ})$, and $\rho_{\mathrm{hv}}(C C)$ is anomalously low $(<0.85)$, indicative of nonmeteorological targets. Because of its close proximity to the low-level mesocyclone, this signature is sometimes confused with the TDS. Recently, a few cases have been observed in which $Z_{\mathrm{DR}}$ is also extremely low $(<-7 \mathrm{~dB}$; e.g., Magsig et al. 2012), though such low $Z_{\mathrm{DR}}$ is rather uncommon. The types of scatterers that cause the signature are unknown, though it is likely that light debris (leaves, dust, etc.) and/or small insects are lofted and ingested into the storm by its intense inflow winds. It remains unclear if the appearance of the signature is related to the inflow (or storm) intensity.

At midlevels, most notable polarimetric signatures are located near the updraft and mesocyclone. Spatially offset to the west or northwest of the $Z_{\mathrm{DR}}$ column is the $K_{\mathrm{DP}}$ column (e.g., Hubbert et al. 1998; Loney et al. 2002; Schlatter 2003; Ryzhkov et al. 2005b; Kumjian and Ryzhkov 2008; Romine et al. 


\section{Low levels ( $\leq 1 \mathrm{~km} \mathrm{AGL)}$

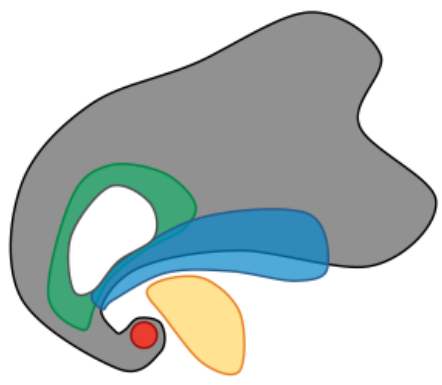 \\ 35-dBZ echo \\ Large hail signature \\ $\mathrm{Z}_{\mathrm{DR}}$ arc \\ $K_{D P}$ foot \\ Inflow signature \\ Tornadic debris signature}

Mid levels $\left(\approx 0^{\circ} \mathrm{C}\right)$

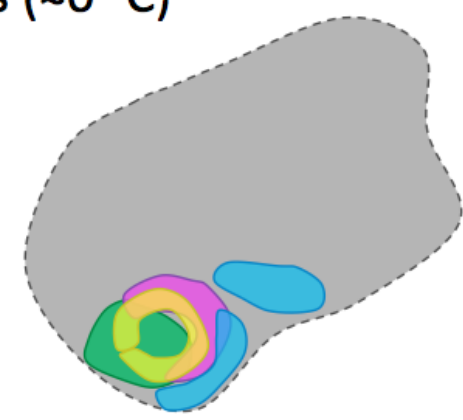

35-dBZ echo

$\mathrm{Z}_{\mathrm{DR}}$ column/ring

Graupel belt

$\mathrm{K}_{\mathrm{DP}}$ column

$\rho_{\text {hv }}$ ring

\section{Upper levels $\left(2.5-5.0 \mathrm{~km}\right.$ above $\left.0^{\circ} \mathrm{C}\right)$}

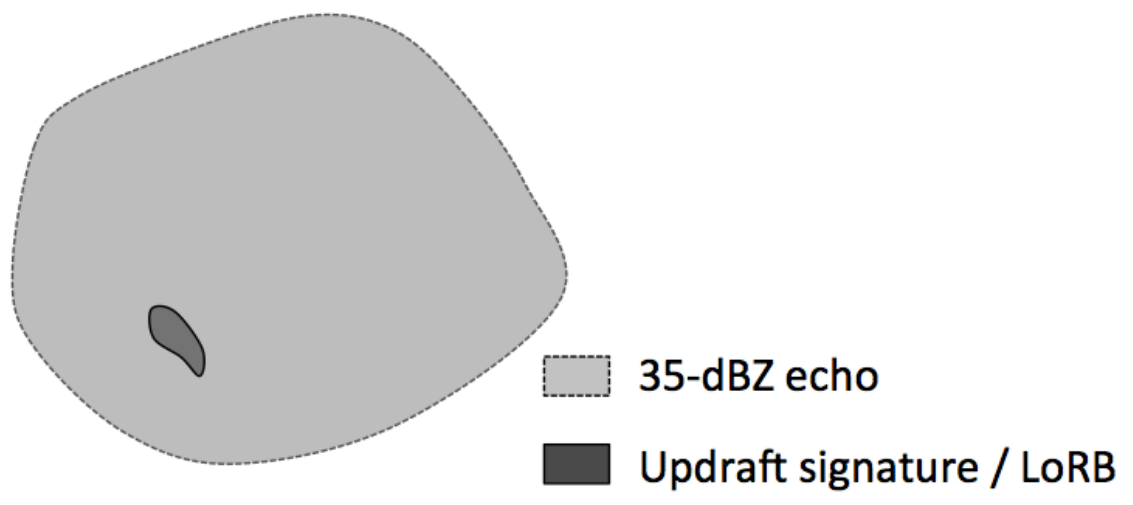

Figure 8. Schematic of polarimetric signatures in supercells at low levels $(\leq 1 \mathrm{~km})$, midlevels (approximately at the environmental $0^{\circ} \mathrm{C}$ level $)$, and upper levels $\left(2.5\right.$ to $5.0 \mathrm{~km}$ above the environmental $0^{\circ} \mathrm{C}$ level). Adapted from Kumjian and Ryzhkov (2008), with updates based on Romine et al. (2008), Kumjian et al. (2010b), and Snyder et al. (2013).

2008; Kumjian et al. 2010b; Snyder et al. 2013). Despite their close proximity to $Z_{\mathrm{DR}}$ columns, the concentrations and types of hydrometeors present in $K_{\mathrm{DP}}$ columns differ significantly, as $K_{\mathrm{DP}}$ columns are dominated by large concentrations of small and medium-sized raindrops and melting ice particles (1-4 $\mathrm{mm})$. Also unlike $Z_{\mathrm{DR}}$ columns, $K_{\mathrm{DP}}$ columns typically are associated with downdraft regions.

As mentioned above, the $Z_{\mathrm{DR}}$ column can be distorted into a ring or half-ring shape by the mesocyclone in supercells (e.g., Kumjian and Ryzhkov 2008; Payne et al. 2010; Palmer et al. 2011; Snyder et 
al. 2013). Nearly collocated with the $Z_{\mathrm{DR}}$ ring is a circular or semi-circular ring of depressed $\rho_{\mathrm{hv}}(C C)$ values called the " $\rho_{\mathrm{hv}}$ ring" (or " $C C$ ring"). Taken together, these signatures indicate mixed-phase and/or non-Rayleigh scatterers within or very near the updraft and mesocyclone. Payne et al. (2010) confirmed the association between these signatures and the mesocyclonic vertical vorticity maximum, and also documented a U-shaped region of lightning activity associated with the signatures, which they termed a "lightning ring."

On the southern flank of the updraft, a region of modest $Z_{H}$, low $Z_{\mathrm{DR}}$, and high $\rho_{\mathrm{hv}}(C C)$ is sometimes observed. The polarimetric measurements suggest that graupel is the dominant hydrometeor type, with a source region in flanking line convective turrets (Kumjian et al. 2010b). Termed the "graupel belt," rapid-scan observations demonstrate that this band of graupel wraps cyclonically around the mesocyclone. Because of the proximity to the $Z_{\mathrm{DR}}$ ring, it is hypothesized that some of this graupel is entrained into the periphery of the updraft, whereupon melting and/or accretion of liquid water contributes to the enhanced $Z_{\mathrm{DR}}$ values observed in the $Z_{\mathrm{DR}}$ ring. Note that this is quite consistent with earlier work suggesting that graupel generated in flanking line turrets serves as hail embryos after entering the updraft (e.g., Heymsfield 1982; Heymsfield and Musil 1982; Nelson 1983).

Finally, at heights between about 2.5 and $5.0 \mathrm{~km}$ above the environmental $0^{\circ} \mathrm{C}$ level, a reduction of $\rho_{\mathrm{hv}}$ $(C C)$ often is observed, typically collocated with high $Z_{H}$ and (sometimes) negative $Z_{\mathrm{DR}}$. It is thought that large hailstones undergoing wet growth contribute to the signature ${ }^{1}$ (e.g., Balakrishnan and Zrnić 1990; Kumjian et al. 2010b; Picca and Ryzhkov 2012; Snyder et al. 2013). Though not strictly collocated with the updraft, the so-called "updraft signature" can serve as a proxy when dual-Doppler wind syntheses are unavailable. Snyder et al. (2013) present observations of a similar signature collected with an X-band polarimetric radar, calling it "Low $\rho_{\text {hv }}$ on the left and rear edge of the bounded weak echo region (BWER)," or "LoRB" for short. They note that the LoRB may be

\footnotetext{
${ }^{1}$ Large $Z_{H}$, negative $Z_{\mathrm{DR}}$, and reduced $\rho_{\mathrm{hv}}(C C)$ are expected for oblate hailstones $>5 \mathrm{~cm}$ ( 2 in) in diameter (see Part I). However, the magnitude of the $\rho_{\mathrm{hv}}(C C)$ reduction is larger than expected based on scattering calculations, implying that perhaps lobes/ protuberances (which form during wet growth) lead to further reductions in $\rho_{\text {hv }}(C C)$ (e.g., Balakrishnan and Zrnić 1990).
}

located as much as $5 \mathrm{~km}$ from the center of the BWER. The presence of such an updraft signature or LoRB may be indicative of a strong updraft and the potential for large hail at the surface in the near future.

\section{Cold-season applications}

The applications of dual-polarization radar observations extend beyond severe convective storms and warm-season precipitation. In this section, applications of polarimetric radar observations in winter or coldseason precipitation are presented.

\section{a. Melting layer detection}

One of the most important uses of dualpolarization data is the detection of the melting layer in stratiform precipitation. Though the conventional "bright band" signature in $Z_{H}$ is sometimes evident (Fig. 9a), the melting layer is unmistakable in fields of $Z_{\mathrm{DR}}$ (Fig. 9b) and especially $C C\left(\rho_{\mathrm{hv}}\right)$ (Fig. 9c). Melting snowflakes first acquire meltwater on the outer portions of the flakes, dramatically increasing their complex refractive index and thus $Z_{H}$. After further melting, the snowflake structure "collapses" (e.g., Knight 1979; Matsuo and Sasyo 1981; Fujiyoshi 1986; Mitra et al. 1990), reducing the size of the flake. This reduction in size and an increase in particle fallspeeds lead to a decrease in $Z_{H}$. $Z_{\mathrm{DR}}$ is maximized beneath the $Z_{H}$ maximum as these collapsed flakes have higher density and take on oblate shapes. The largest melting flakes may reach the size at which resonance scattering occurs, leading to a measurable "blip" in the $\Phi_{\mathrm{DP}}$ owing to backscattered differential phase, $\delta$ (Zrnić et al. 1993; Trömel et al. 2013). This non-Rayleigh scattering, combined with a diversity of particle types and shapes (partially melted snowflakes, totally melted small drops, etc.) leads to a reduction of $\rho_{\text {hv }}(C C)$ near the bottom of the melting layer (Fig. 9c).

The MLDA implemented as part of the WSR-88D upgrade utilizes $Z_{H}, Z_{\mathrm{DR}}$, and $C C\left(\rho_{\mathrm{hv}}\right)$ at high antenna elevation angles $\left(4^{\circ}-10^{\circ}\right)$ to detect the melting layer top and bottom (assuming widespread stratiform precipitation near or over the radar) and generally agrees well with the melting layer top inferred from observed soundings or short-term model output (Giangrande et al. 2008). Additionally, it has the advantage of improved spatial and temporal resolution over sounding- or model-based estimates. The MLDA performance may deteriorate when there exists large azimuthal variations of the melting layer characteristics, in the presence of multiple melting layers 


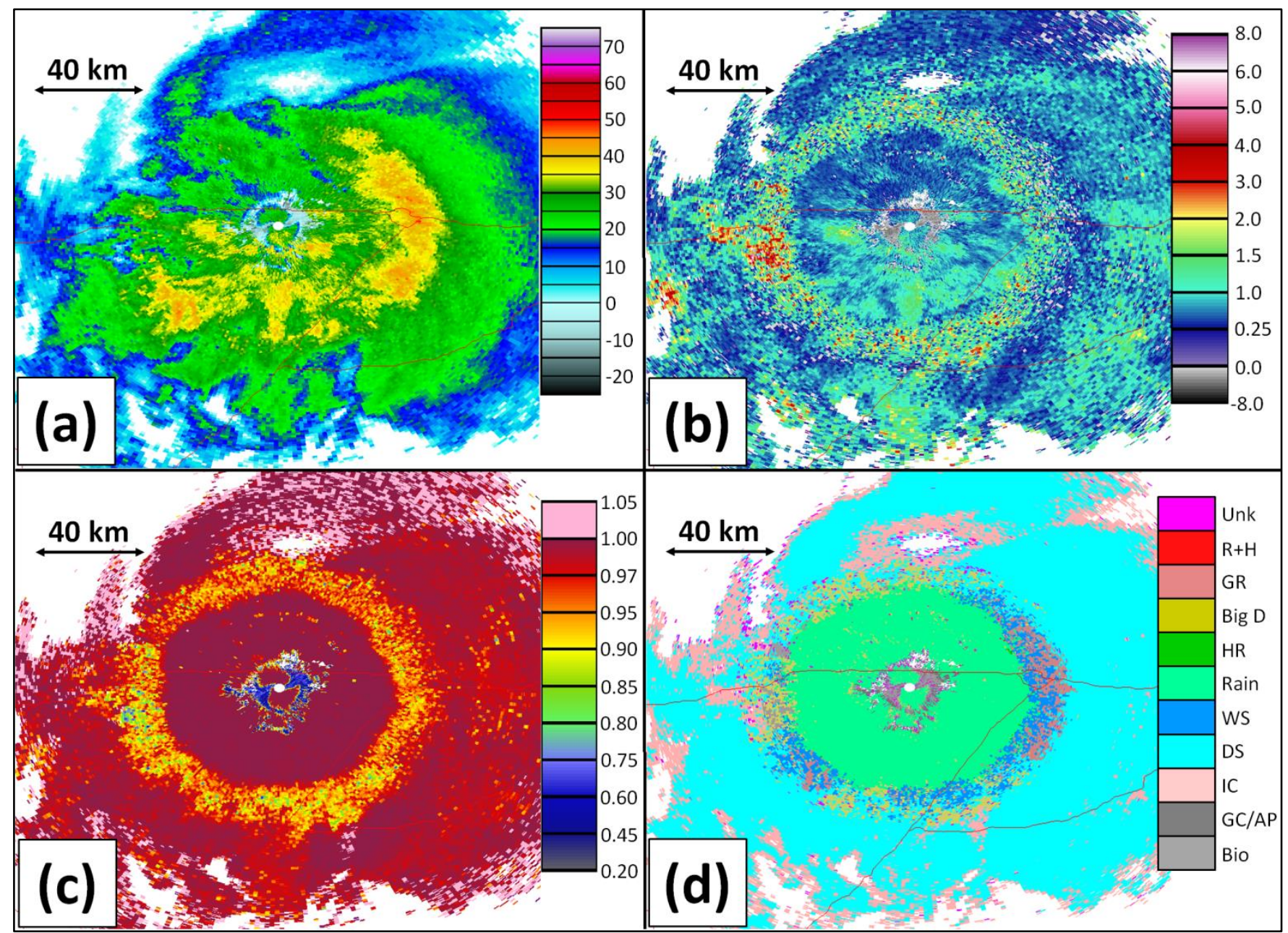

Figure 9. Four-panel display of the $3.43^{\circ}$ PPI taken at 1502 UTC 14 August 2012 from the polarimetric WSR-88D radar near Topeka, KS (KTWX). Fields shown are (a) $Z_{H}$, (b) $Z_{\mathrm{DR}}$, (c) $\rho_{\mathrm{hv}}(C C)$, and (d) HCA. The melting layer bright band is evident in all fields. Note the predominance of "wet snow" (dark blue) classified in the melting layer.

(e.g., Ikeda et al. 2005), or in convection. In the latter case, well-defined melting layers are often absent. Recall that the MLDA is a key component of the HCA discussed in section 3a (Fig. 9d), and thus also plays a role in the dual-polarization QPE algorithm. Future builds of the National Weather Service WSR-88D radar product generator will implement changes that should help improve performance of the MLDA.

\section{b. Snow crystal growth regions}

Polarimetric radar observations in winter precipitation have revealed a signature aloft associated with planar or dendritic crystals (e.g., Bader et a. 1987; Ryzhkov and Zrnić 1998; Wolde and Vali 2001; Hogan et al. 2002; Moisseev et al. 2009; Kennedy and Rutledge 2011; Andrić et al. 2013; Bechini et al. 2013; Schneebeli et al. 2013). The signature appears as an enhancement of $Z_{\mathrm{DR}}$ (Fig. 10b; also seen in Fig. 9) and
$K_{\mathrm{DP}}$ (on the order of a few tenths of a deg $\mathrm{km}^{-1}$ at $\mathrm{S}$ band; Fig. 10c), and slightly decreased $C C$ (Fig. 10d; typically $>0.95$, though lower on occasion), whereas $Z_{H}$ generally increases throughout the layer. Recently, several papers have explored this signature with observations and modeling (Kennedy and Rutledge 2011; Andrić et al. 2013). Though neither modeling effort was able to reproduce quantitatively all variables, both agree that the enhancements are caused by pristine ice crystals (likely dendrites) undergoing deposition growth. The enhancements disappear as aggregation takes over and the $Z_{H}$ increases and $Z_{\mathrm{DR}}$ decreases towards the ground. Kennedy and Rutledge (2011) and Bechini et al. (2013) found that these "pockets" of enhanced $Z_{\mathrm{DR}}$ and $K_{\mathrm{DP}}$ aloft are associated with increased precipitation rates (and, assuming a temperature profile that supports it, heavy snow) at the surface. Thus, the development of these signatures 


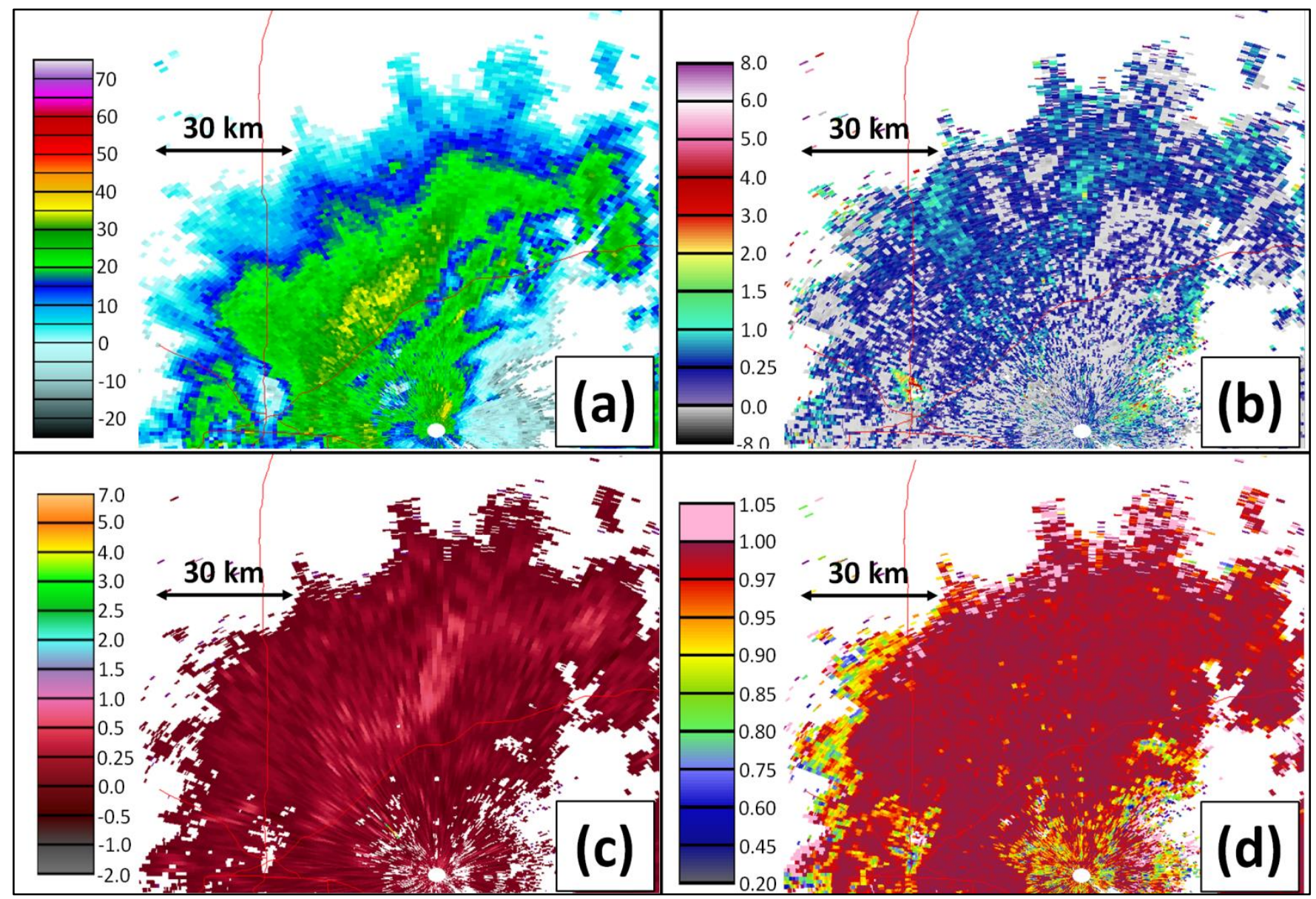

Figure 10. Four-panel display of the $2.4^{\circ}$ elevation PPI from 0001 UTC 11 November 2012, taken with the polarimetric WSR-88D radar near Denver, CO (KFTG). Fields shown are (a) $Z_{H}$, (b) $Z_{\mathrm{DR}}$, (c) $K_{\mathrm{DP}}$, and (d) $C C$ or $\rho_{\mathrm{hv}}$. Note that the enhancement north of the radar corresponds to temperature levels between about $-12^{\circ} \mathrm{C}$ and $-17^{\circ} \mathrm{C}$ (from the $0000 \mathrm{UTC}$ Denver, $\mathrm{CO}$, sounding).

aloft may serve as a precursor to enhanced surface precipitation rates downstream.

\section{c. Snow crystal identification}

As we have seen, polarimetry allows for added information regarding the mean shapes of particles within the sampling volume. In winter precipitation, often there are a number of different snow crystal habits that may be observed, indicating crystal growth at different height levels (temperature regions). Once these snow crystals aggregate, the polarimetric contrasts of the resulting flakes are minimized and thus the information is lost. However, observations routinely reveal that the edges of precipitation echoes often maintain enhanced values of $Z_{\mathrm{DR}}$ (Fig. 11). This provides insight into the types of crystals that are being aggregated in the higher- $Z_{H}$ center of the echo. Recall that for a given particle shape, $Z_{\mathrm{DR}}$ increases with increasing complex relative permittivity. For dry snow crystals, this increase in dielectric constant is achieved by increased particle density. Electromagnetic scattering calculations reveal that the $Z_{\mathrm{DR}}$ of higher-density snow crystals, such as plates, is larger than lower-density particles of the same minor-tomajor axis ratio such as dendrites or needles (e.g., Hogan et al. 2002; Andrić et al. 2013; Thompson et al. 2014). At $S$ band, observations of $Z_{\mathrm{DR}}$ in excess of 5-6 $\mathrm{dB}$ in winter storms are associated with plate-like crystals (hexagonal plates were observed at the ground east of Wichita during the example shown in Fig. 11; T. Dewvall 2012, personal communication). Research is underway to determine if such information on crystal habit can be used to improve estimates of snowfall rate and/or liquid water equivalency.

As mentioned above, once aggregation occurs, the informative content of $Z_{\mathrm{DR}}$ for crystal identification is lost. This is true even if aggregates are mixed with pristine snow crystals within the sampling volume, because the large size of aggregates dominates the 


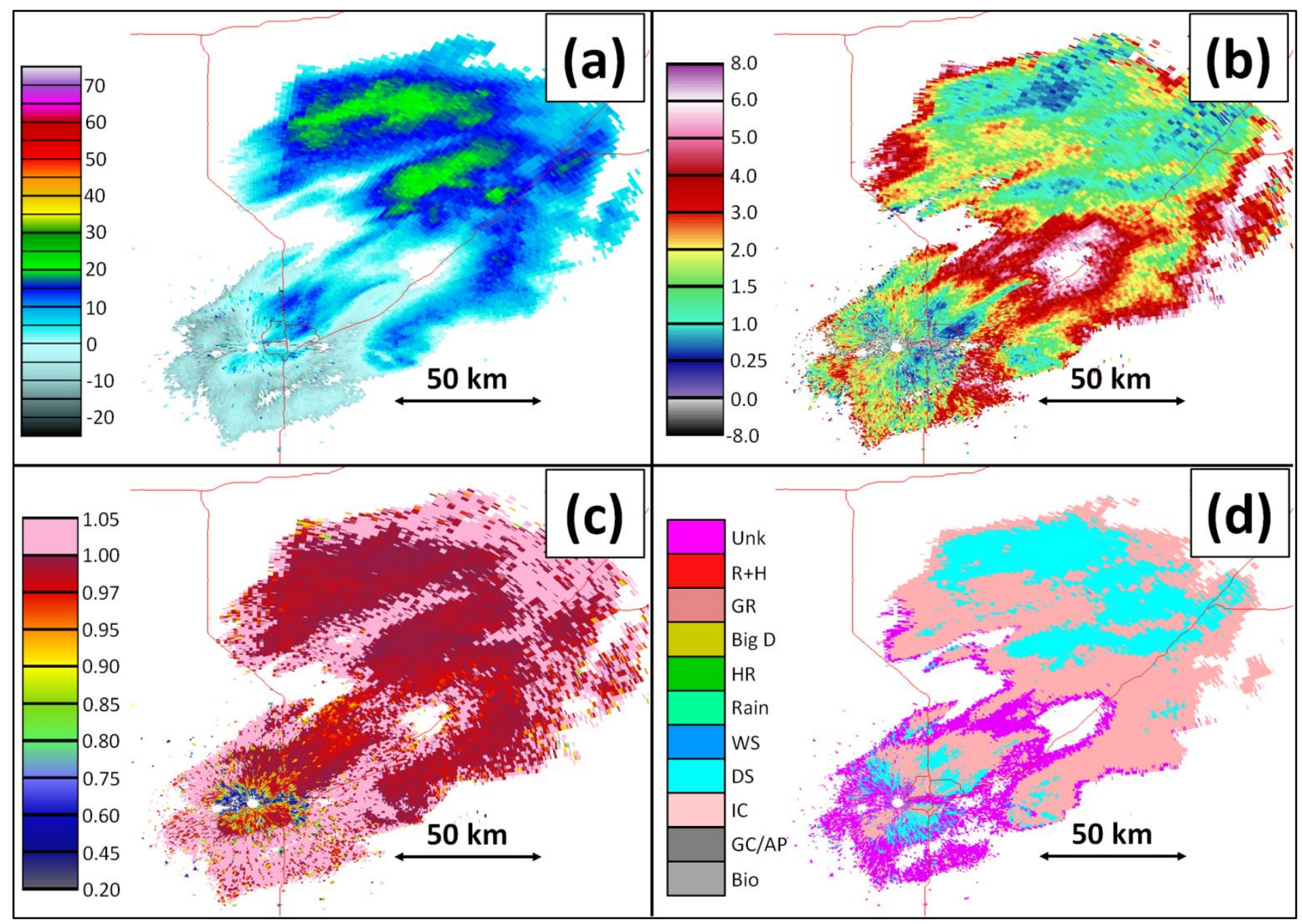

Figure 11. PPI display from a winter storm, observed with the polarimetric WSR-88D radar near Wichita, KS (KICT). Data are from the $0.615^{\circ}$ elevation angle at 0210 UTC 8 February 2012 . Hexagonal plates were observed at the ground east of the radar, associated with the very high $Z_{\mathrm{DR}}$ regions. Fields shown are (a) $Z_{H}$, (b) $Z_{\mathrm{DR}}$, (c) $\rho_{\mathrm{hv}}$ or $C C$, and (d) HCA.

contribution to the total $Z_{H}$ (e.g., Bader et al. 1987; Ryzhkov and Zrnić 1998; Wolde and Vali 2001; Andrić et al. 2013), and $Z_{\mathrm{DR}}$ is the reflectivityweighted measure of particle shape. However, fluffy snow aggregates are relatively "transparent" to the propagation differential phase, owing to their very low density (and thus very low relative permittivity). On the other hand, some pristine crystals have much higher density and can produce measurable $\Phi_{\mathrm{DP}}$ or $K_{\mathrm{DP}}$ (cf. Fig. 10c). In fact, it is possible to quantitatively estimate the ice crystal mass content when mixed with aggregates (e.g., Ryzhkov et al. 1998) or other hydrometeors with intrinsic low $K_{\mathrm{DP}}$ such as ice pellets (e.g., Kumjian et al. 2013). Estimation of the ice crystal mass content may be important for identifying aviation hazards, as large quantities of ice crystals recently have received attention as a possible concern for aircraft engines (e.g., Addy and Veres 2011).

\section{d. Precipitation type transition}

Because polarimetric radar can be used to discriminate between various types of precipitation, it has great potential to be used in transitional winter precipitation events to delineate regions of precipitation type changeovers (e.g., melting snow to rain, dry snow to melting snow, freezing rain to ice pellets). Figure 12 is an example of a complex winter event near Long Island, New York. The PPI of $Z_{H}$ alone (Fig. 12a) indicates several areas of enhanced values, but it is ambiguous which areas are heavy snow, and which are a result of "bright banding" in melting snow. The informative content of the polarimetric variables (Fig. $12 \mathrm{~b}-\mathrm{d})$ combined with thermodynamic information from soundings and surface data (not shown) reveals that the high- $Z_{H}$ band north of the radar is dry snow (near-zero $Z_{\mathrm{DR}}$, high $C C$ ), whereas the complex structure south of the radar is a result of wet snow 


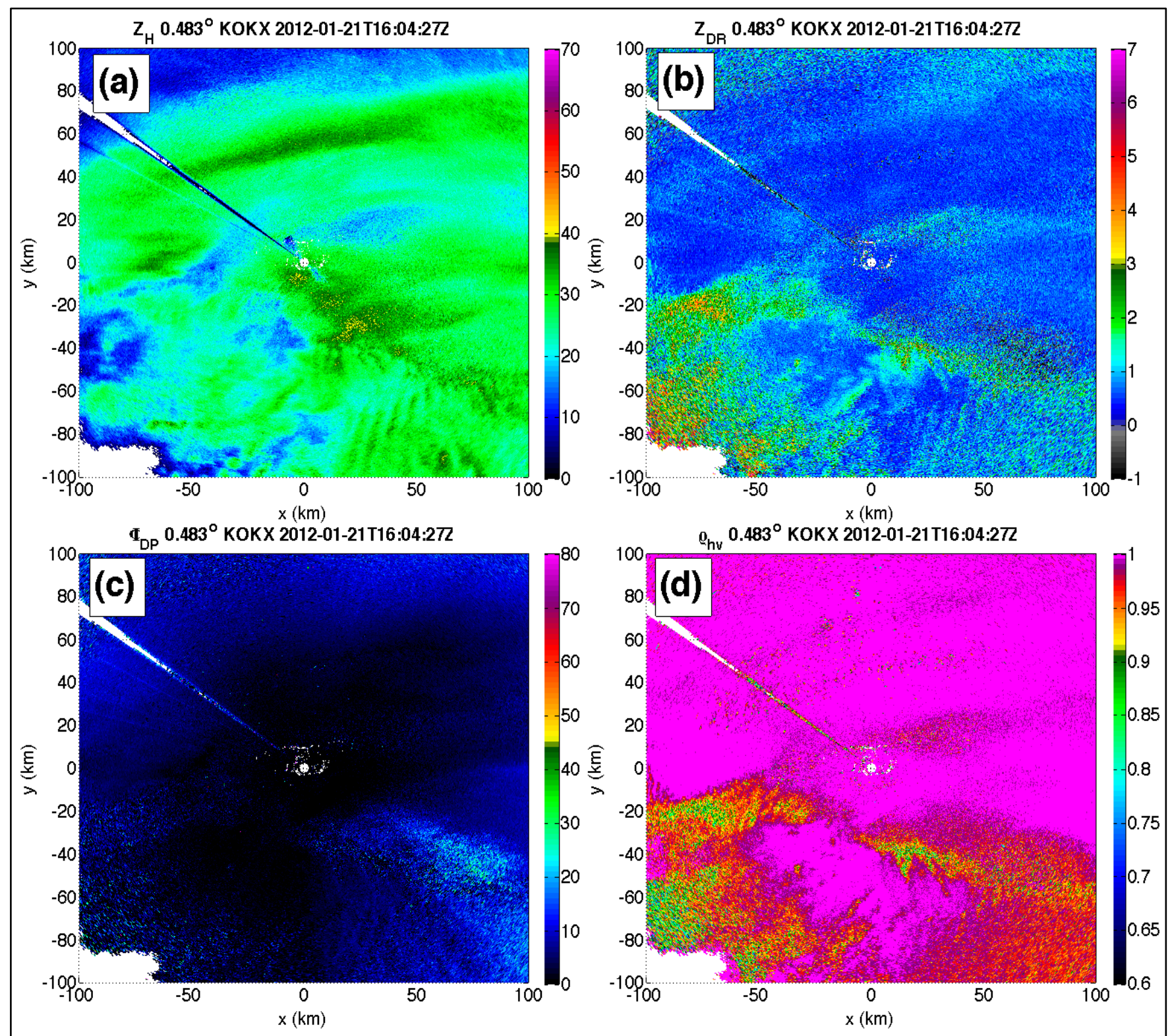

Figure 12. PPI display from the polarimetric WSR-88D radar on Long Island, NY (KOKX). Data from the $0.483^{\circ}$ elevation angle, taken at 1604 UTC 21 January 2012. The data reveal a complex scenario with several precipitation type transitions. See text for details. Fields shown are (a) $Z_{H}$, (b) $Z_{\mathrm{DR}}$, (c) $\Phi_{\mathrm{DP}}$, and (d) $\rho_{\mathrm{hv}}(C C$ ). Note that these are level-II data collected the day after the upgrade of the radar became operational. Level-III data were not available from the NCDC archive for this case.

(high $Z_{\mathrm{DR}}$ and reduced $C C$ ) surrounding a region of rain and/or freezing rain (high $C C$ surrounded by reduced values). The northernmost band of wet snow (reduced $C C$ ) pushed northwards in time, causing a changeover of surface precipitation type across Long Island. National Weather Service forecasters were able to use the polarimetric radar data to discern the different precipitation types in this case, which helped them fine tune short-term forecasts that benefited the public and emergency officials, among others (J. Picca 2012, personal communication).
In addition to the known ability to distinguish between rain and snow at the surface, a recently discovered signature may mark the transition between freezing rain and ice pellets (Fig. 13; see also Kumjian et al. 2013). In at least four cases from Oklahoma, a low-level enhancement of $Z_{\mathrm{DR}}$ was observed while ice pellets were observed at the surface. This so-called "refreezing signature" is associated with a 6-7 dB decrease in $Z_{H}$, a slight increase in $\Phi_{\mathrm{DP}}$ (and $K_{\mathrm{DP}}$ ), and an observable reduction of $C C$. One would expect a decrease in $\Phi_{\mathrm{DP}}\left(K_{\mathrm{DP}}\right)$ and $Z_{\mathrm{DR}}$ during freezing, owing 

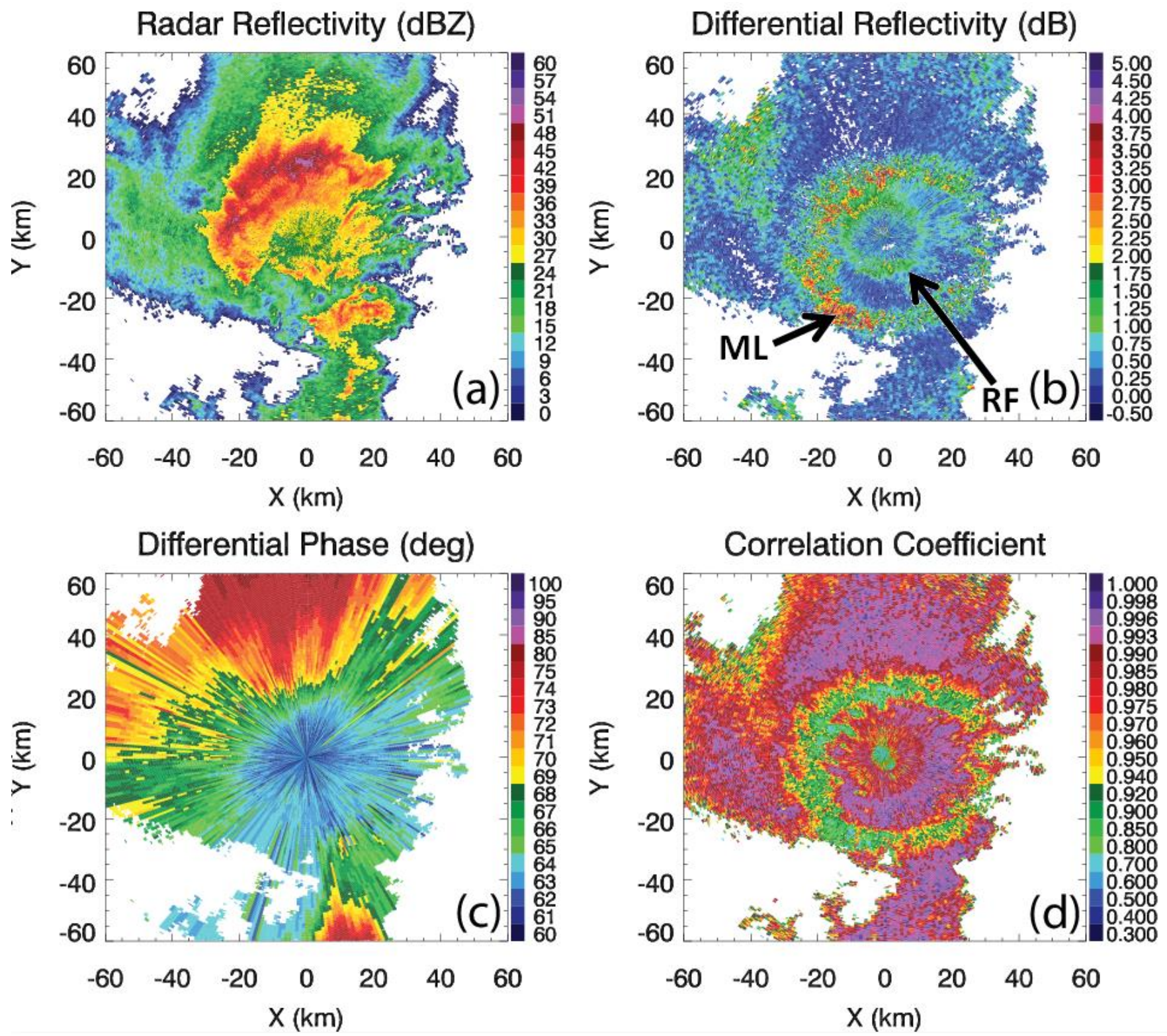

Figure 13. PPI display of the dual-polarization radar variables, taken at 1406 UTC 30 November 2006, at $4.3^{\circ}$ elevation. Data are from the research polarimetric WSR-88D radar in Norman, OK (KOUN). Figure adapted from Kumjian et al. (2013). Fields shown are (a) $Z_{H}$, (b) $Z_{\mathrm{DR}}$, (c) $\Phi_{\mathrm{DP}}$, and (d) $C C\left(\rho_{\mathrm{hv}}\right)$. Arrows in panel (b) indicate the enhancements in $Z_{\mathrm{DR}}$ associated with the melting layer (ML) and the refreezing signature $(\mathrm{RF})$.

to the decrease in complex dielectric factor and increased tumbling of the ice pellets. Though the exact mechanism causing the signature is not known, Kumjian et al. (2013) hypothesize that (i) preferential refreezing of the smallest drops first leads to an enhancement of $Z_{\mathrm{DR}}$ similar to size sorting or evaporation, and slowing of the particles as they begin to freeze leads to a very slight increase in $K_{\mathrm{DP}}$; and/or (ii) generation and subsequent depositional growth of columnar or needle-like crystals leads to a local enhancement of $Z_{\mathrm{DR}}$ and $K_{\mathrm{DP}}$. More research using additional cases is needed to refine the interpretation and detection of this potentially useful radar signature that marks the changeover from typically very highimpact freezing rain to comparatively harmless ice pellets. Because refreezing occurs at low levels, the signature is located at close range to the radar. It is best to observe the refreezing signature at intermediate elevation angles $\left(2-4^{\circ}\right)$ to avoid low-level beam blockage or ground clutter that may interfere with its detection. 


\section{Conclusion}

This paper has reviewed signatures and applications of polarimetric radar data in warm- and coldseason precipitation. This includes the hydrometeor classification algorithm, improved quantitative precipitation estimation, the melting layer detection algorithm, detection of transition regions in winter precipitation, hail detection and sizing, and the tornadic debris signature. In addition, signatures in supercell storms and winter precipitation that have special diagnostic value were discussed. Though this review is by no means exhaustive, it is clear from the sampling provided above that polarimetric radar observations have a rich and wide range of applications, and provide invaluable information for operations and research. Future research and development will continue to enhance the tools at the disposal of meteorologists and emergency managers, as well as uncover new signatures and applications.

Acknowledgments. I thank Dr. Alexander Ryzhkov (Cooperative Institute for Mesoscale Meteorological Studies, CIMMS)/(National Severe Storms Laboratory, NSSL) for discussions on upcoming QPE improvements. Joey Picca (NWS New York) is thanked for his involvement with the KOKX case and for many discussions about this case and polarimetry in general, as well as for reviewing drafts of this series. I greatly appreciate Tyler Dewvall (AccuWeather Enterprise Solutions) for his willingness to go out in the snow and to make crystal habit observations for the KICT snow case. Dr. Scott Ellis (National Center for Atmospheric Research, NCAR), Dr. Matt Bunkers (NWS Rapid City), Scott Ganson (NWS Radar Operations Center), Professor Paul Smith (South Dakota School of Mines and Technology), and Paul Schlatter (NWS Program Coordination Office) are thanked for their reviews of the manuscript. Jon Zeitler (NWS Austin/San Antonio) provided a constructive technical edit of the manuscript. Support for the author comes from the NCAR Advanced Study Program and from NSF Grant AGS-1143948. NCAR is sponsored by the National Science Foundation.

\section{REFERENCES}

Addy, H. E., and J. P. Veres, 2011: An overview of NASA engine ice-crystal icing research. International Conf. on Aircraft and Engine Icing and Ground Deicing. SAE International, Chicago, 2011-38-0017, 13 pp. [Available online at ntrs.nasa.gov/archive/nasa/casi. ntrs.nasa.gov/20110023761_2011025037.pdf.]

Anderson, M. E., L. D. Carey, W. A. Petersen, and K. R. Knupp, 2011: C-band dual-polarimetric radar signatures of hail. Electronic J. Operational Meteor., $12(2), 1-30$.

Andrić, J., M. R. Kumjian, D. S. Zrnić, J. M. Straka, and V. M. Melnikov, 2013: Polarimetric signatures above the melting layer in winter storms: An observational and modeling study. J. Appl. Meteor. Climatol., 52, 682700.

Aydin, K., T. A. Seliga, and V. Balaji, 1986: Remote sensing of hail with a dual linear polarized radar. $J$. Climate Appl. Meteor., 25, 1475-1484.

Bader, M. J., S. A. Clough, and G. P. Cox, 1987: Aircraft and dual polarization radar observations of hydrometeors in light stratiform precipitation. Quart. J. Roy. Meteor. Soc., 113, 491-515.

Balakrishnan, N. and D. S. Zrnić, 1990: Use of polarization to characterize precipitation and discriminate large hail. J. Atmos. Sci., 47, 1525-1540.

Battan, L. J., 1973: Radar Observations of the Atmosphere. Univ. of Chicago Press, 324 pp.

Bechini, R., L. Baldini, and V. Chandrasekar, 2013: Observations of differential propagation phase in the ice region of precipitating clouds at C-band and Xband radar frequencies. J. Appl. Meteor. Climatol., 52, 1147-1169.

Blair, S. F., D. R. Deroche, J. M. Boustead, J. W. Leighton, B. L. Barjenbruch, and W. P. Gargan, 2011: A radarbased assessment of the detectability of giant hail. Electronic J. Severe Storms Meteor., 6 (7), 1-30.

, J. M. Laflin, J. W. Leighton, and D. R. Deroche, 2012: S-band polarimetric analysis of the 23 May 2011 Oklahoma record hailstorm using high-resolution observations during HailSTONE. Recorded presentation, 26th Conf. on Severe Local Storms, Nashville, TN, Amer. Meteor. Soc., 16.6. [Available online at ams.confex.com/ams/26SLS/webprogram/ Paper211473.html.]

Bluestein, H. B., M. M. French, R. L. Tanamachi, S. J. Frasier, K. Hardwick, F. Junyent, and A. L. Pazmany, 2007: Close-range observations of tornadoes in supercells made with a dual-polarization, X-band, mobile Doppler radar. Mon. Wea. Rev., 135, 15221543.

Bodine, D. J., M. R. Kumjian, A. J. Smith, R. D. Palmer, A. V. Ryzhkov, and P. L. Heinselman, 2011: Highresolution polarimetric observations of an EF-4 tornado on 10 May 2010 from OU-PRIME. Preprints, 35th Conf. on Radar Meteorology, Pittsburgh, PA, Amer. Meteor. Soc., 3B.4. [Available online at ams.confex.com/ams/35Radar/webprogram/Manuscrip t/Paper191661/tds_paper_amsradar.pdf.]

R. D. Palmer, P. L. Heinselman, and A. V. Ryzhkov, 2013: Tornado damage estimation using polarimetric radar. Wea. Forecasting, 28, 139-158.

Brandes, E. A., J. Vivekanandan, J. D. Tuttle, and C. J. Kessinger, 1995: A study of thunderstorm microphysics with multiparameter radar and aircraft 
observations. Mon. Wea. Rev., 123, 3129-3143.

Bringi, V. N., and V. Chandrasekar, 2001: Polarimetric Doppler Weather Radar: Principles and Applications. Cambridge University Press, 636 pp.

J. Vivekanandan, and J. D. Tuttle, 1986: Multiparameter radar measurements in Colorado convective storms. Part II: Hail detection studies. J. Atmos. Sci., 43, 2564-2577.

D. A. Burrows, and S. M. Menon, 1991: Multiparameter radar and aircraft study of raindrop spectral evolution in warm-based clouds. J. Appl. Meteor., 30, 853-880.

, K. Knupp, A. Detwiler, L. Liu, I. J. Caylor, R. A. Black, 1997: Evolution of a Florida Thunderstorm during the Convection and Precipitation/Electrification Experiment: The Case of 9 August 1991. Mon. Wea. Rev., 125, 2131-2160.

Carey, L. D., W. A. Petersen, M. Thurai, M. E. Anderson, E. V. Schultz, C. J. Schultz, and K. Knupp, 2010: Precipitation properties of a cool-season tornadic storm inferred from C-band dual-polarimetric radar and 2D-video disdrometer observations. Preprints, 25th Conf. on Severe Local Storms, Denver, CO, Amer. Meteor. Soc., 15.5. [Available online at ams.confex.com/ams/pdfpapers/175764.pdf.]

Caylor, I. J., and A. J. Illingworth, 1987: Radar observations and modelling of warm rain initiation. Quart. J. Roy. Meteor. Soc., 113, 1171-1191.

Conway, J. W., and D. S. Zrnić, 1993: A study of embryo production and hail growth using dual-Doppler and multiparameter radars. Mon. Wea. Rev., 121, 25112528.

Crowe, C. C., C. J. Schultz, M. Kumjian, L. D. Carey, and W. A. Petersen, 2012: Use of dual-polarization signatures in diagnosing tornadic potential. Electronic J. Operational Meteor., 13 (5), 57-78.

Dawson, D. T., E. R. Mansell, Y. Jung, L. J. Wicker, M. R. Kumjian, and M. Xue, 2013: Low-level $\mathrm{Z}_{\mathrm{DR}}$ signatures in supercell forward flanks: The role of size sorting and melting of hail. J. Atmos. Sci., in press.

Dolan, B., and S. A. Rutledge, 2009: A theory-based hydrometeor identification algorithm for X-band polarimetric radars. J. Atmos. Oceanic Technol., 26, 2071-2088.

, S. Lim, V. Chandrasekar, and M. Thurai, 2013: A robust C-band hydrometeor identification algorithm and application to a long term polarimetric radar data set. J. Appl. Meteor. Climatol., 52, 2162-2186.

Doviak, R. J., and D. S. Zrnić, 1993: Doppler Radar and Weather Observations. Dover Publications, 562 pp.

Elmore, K. L., 2011: The NSSL hydrometeor classification algorithm in winter surface precipitation: Evaluation and future development. Wea. Forecasting, 26, 756765.

Flamig, Z., J. J. Gourley, K. L. Elmore, and L. Rothfusz, 2013: Crowdsourcing precipitation types at the ground with mPing. Recorded presentation, 36th Conf. on Radar Meteorology, Breckenridge, CO, Amer. Meteor. Soc., 11A.1. [Available online at ams.confex.com/ ams/36Radar/webprogram/Paper229121.html.]

Fujiyoshi, Y., 1986: Melting snowflakes. J. Atmos. Sci., 43, 307-311.

Giangrande, S. E., and A. V. Ryzhkov, 2008: Estimation of rainfall based on the results of polarimetric echo classification. J. Appl. Meteor. Climatol., 47, 24452462.

, J. M. Krause, and A. V. Ryzhkov, 2008: Automatic designation of the melting layer with a polarimetric prototype of the WSR-88D radar. J. Appl. Meteor. Climatol., 47, 1354-1364.

Hall, M. P. M., J. W. F. Goddard, and S. M. Cherry, 1984: Identification of hydrometeors and other targets by dual-polarization radar. Radio. Sci., 19, 132-140.

Heinselman, P. L., and A. V. Ryzhkov, 2006: Validation of polarimetric hail detection. Wea. Forecasting, 21, 839-850.

Herzegh, P. H., and A. R. Jameson, 1992: Observing precipitation through dual-polarization radar measurements. Bull. Amer. Meteor. Soc., 73, 13651374.

Heymsfield, A. J., 1982: A comparative study of the rates of development of potential graupel and hail embryos in High Plains storms. J. Atmos. Sci., 39, 2867-2897. , and D. J. Musil, 1982: Case study of a hailstorm in Colorado. Part II: Particle growth processes at midlevels deduced from in-situ measurements. J. Atmos. Sci., 39, 2847-2866.

Heymsfield, G. M., L. Tian, L. Li, M. McLinden, and J. I. Cervantes, 2013: Airborne radar observations of severe hail storms: Implications for future spaceborne radar. J. Appl. Meteor. Climatol., 52, 1851-1867.

Hogan, R., P. Field, A. Illingworth, R. Cotton, and T. Choularton, 2002: Properties of embedded convection in warm-frontal mixed-phase cloud from aircraft and polarimetric radar. Quart. J. Roy. Meteor. Soc., 128, 451-476.

Höller, H., M. Hagen, P. F. Meischner, V. N. Bringi, and J. Hubbert, 1994: Life cycle and precipitation formation in a hybrid-type hailstorm revealed by polarimetric and Doppler radar measurements. J. Atmos. Sci., 51, 2500-2522.

Hubbert, J. C., V. N. Bringi, L. D. Carey, and S. Bolen, 1998: CSU-CHILL polarimetric radar measurements from a severe hail storm in eastern Colorado. J. Appl. Meteor., 37, 749-775.

Ikeda, K., E. A. Brandes, and R. M. Rasmussen, 2005: Polarimetric radar observation of multiple freezing levels. J. Atmos. Sci., 62, 3624-3636.

Illingworth, A. J., J. W. F. Goddard, and S. M. Cherry, 1987: Polarization radar studies of precipitation development in convective storms. Quart. J. Roy. Meteor. Soc., 113, 469-489. 
Jameson, A. R., M. J. Murphy, and E. P. Krider, 1996: Multiple parameter radar observations of isolated Florida thunderstorms during the onset of electrification. J. Appl. Meteor., 35, 343-354.

Jung, Y., M. Xue, and G. Zhang, 2010: Simulations of polarimetric radar signatures of a supercell storm using a two-moment bulk microphysics scheme. $J$. Appl. Meteor. Climatol., 49, 146-163.

Kennedy, P. C., and S. A. Rutledge, 2011: S-band dualpolarization radar observations of winter storms. $J$. Appl. Meteor. Climatol., 50, 844-858.

W. A. Petersen, and V. N. Bringi, 2001: Polarimetric radar observations of hail formation. $J$. Appl. Meteor., 40, 1347-1366.

Knight, C. A., 1979: Observations of the morphology of melting snow. J. Atmos. Sci., 36, 1123-1130.

Kollias, P., B. A. Albrecht, and F. D. Marks Jr., 2001: Raindrop sorting induced by vertical drafts in convective clouds. Geophys. Res. Lett., 28, 27872790 .

Kumjian, M. R., 2011: Precipitation properties of supercell hook echoes. Electronic J. Severe Storms Meteor., 6 (5), 1-21.

2013a: Principles and applications of dualpolarization weather radar. Part I: Description of the polarimetric radar variables. J. Operational Meteor., 1 (19), 226-242.

2013b: Principles and applications of dualpolarization weather radar. Part III: Artifacts. J. Operational Meteor., 1 (21), 265-274.

, and A. V. Ryzhkov, 2008: Polarimetric signatures in supercell thunderstorms. J. Appl. Meteor. Climatol., 47, 1940-1961.

, and _, 2009: Storm-relative helicity revealed from polarimetric radar measurements. J. Atmos. Sci., 66, $667-685$.

, and _ 2012: The impact of size sorting on the polarimetric radar variables. J. Atmos. Sci., 69, 20422060.

, J. C. Picca, S. M. Ganson, A. V. Ryzhkov, J. Krause, D. Zrnić, and A. Khain, 2010a: Polarimetric radar characteristics of large hail. Preprints, 25th Conf. on Severe Local Storms, Denver, CO, Amer. Meteor. Soc., 11.2. [Available online at ams.confex.com/ams/ pdfpapers/176043.pdf.]

, A. V. Ryzhkov, V. M. Melnikov, and T. J. Schuur, 2010b: Rapid-scan super-resolution observations of a cyclic supercell with a dual-polarization WSR-88D. Mon. Wea. Rev., 138, 3762-3786.

, K. L. Ortega, A. V. Ryzhkov, J. Krause, and S. Ganson, 2012a: Polarimetric radar observations and microphysical model simulations of melting hail. Recorded presentation, 26th Conf. on Severe Local Storms, Nashville, TN, Amer. Meteor. Soc., 11B.1. [Available online at ams.confex.com/ams/26SLS/ webprogram/Paper212194.html.]
S. M. Ganson, and A. V. Ryzhkov, 2012b: Freezing of raindrops in deep convective updrafts: A microphysical and polarimetric model. J. Atmos. Sci., 69, 3471-3490.

, A. V. Ryzhkov, H. D. Reeves, and T. J. Schuur, 2013: A dual-polarization radar signature of hydrometeor refreezing in winter storms. J. Appl. Meteor. Climatol., 52, 2549-2566.

Lim, S., V. Chandrasekar, and V. N. Bringi, 2005: Hydrometeor classification system using dualpolarization radar measurements: Model improvements and in situ verification. IEEE Trans. Geosci. Remote Sens., 43, 792-801.

Liu, H., and V. Chandrasekar, 2000: Classification of hydrometeors based on polarimetric radar measurements: Development of fuzzy logic and neurofuzzy systems, and in situ verification. J. Atmos. Oceanic Technol., 17, 140-164.

Loney, M. L., D. S. Zrnić, J. M. Straka, and A. V. Ryzhkov, 2002: Enhanced polarimetric radar signatures above the melting level in a supercell storm. J. Appl. Meteor., 41, 1179-1194.

Magsig, M. A., J. G. LaDue, C. D. Payne, and L. R. Lemon, 2012: Strongly negative $Z_{D R}$ signatures in low levels of deep convection. Poster presentation, 26th Conf. on Severe Local Storms, Nashville, TN, Amer. Meteor. Soc., 56.

Mahale, V. N., J. A. Brotzge, and H. B. Bluestein, 2012: An analysis of vortices embedded within a quasi-linear convective system using X-band polarimetric radar. Wea. Forecasting, 27, 1520-1537.

Matsuo, T., and Y. Sasyo, 1981: Empirical formula for the melting rate of snowflakes. J. Meteor. Soc. Japan, $\mathbf{5 9}$, $1-9$.

Meischner, P. F., V. N. Bringi, D. Heimann, and H. Höller, 1991: A squall line in southern Germany: Kinematics and precipitation formation as deduced by advanced polarimetric and Doppler radar measurements. Mon. Wea. Rev., 119, 678-701.

Mitra, S. K., O. Vohl, M. Ahr, and H. R. Pruppacher, 1990: A wind tunnel and theoretical study of the melting behavior of atmospheric ice particles. IV: Experiment and theory for snow flakes. J. Atmos. Sci., 47, 584591.

Moisseev, D., E. Saltikoff, and M. Leskinen, 2009: Dualpolarization weather radar observations of snow growth processes. Preprints, 34th Conf. on Radar Meteorology, Williamsburg, VA, Amer. Meteor. Soc., 13B.2. [Available online at ams.confex.com/ams/ pdfpapers/156123.pdf.]

Nelson, S. P., 1983: The influence of storm flow structure on hail growth. J. Atmos. Sci., 40, 1965-1983.

Ortega, K. L., T. M. Smith, K. L. Manross, A. G. Kolodziej, K. A. Scharfenberg, A. Witt, and J. J. Gourley, 2009: The Severe Hazards Analysis and Verification Experiment. Bull. Amer. Meteor. Soc., 90, 1519-1530. 
M. Kumjian, A. Ryzhkov, and J. Krause, 2012: Verification of a small, large, and giant hail discrimination algorithm for dual-polarized WSR-88D radars using high resolution reports. Preprints, 37th Ann. Meeting of the Natl. Wea. Assoc., Madison, WI, P2.24. [Available online at www.nwas.org/meetings/ nwa2012/presentations/NWA2012_P2.24_Ortega_etal .zip.]

Palmer, R. D., and Coauthors, 2011: Observations of the 10 May 2010 tornado outbreak using OU-PRIME: Potential for new science with high-resolution polarimetric radar. Bull. Amer. Meteor. Soc., 92, 871891.

Park, H. S., A. V. Ryzhkov, D. S. Zrnić, and K.-Y. Kim, 2009: The hydrometeor classification algorithm for the polarimetric WSR-88D: Description and application to an MCS. Wea. Forecasting, 24, 730-748.

Payne, C. D., T. J. Schuur, D. R. MacGorman, M. I. Biggerstaff, K. M. Kuhlman, and W. D. Rust, 2010: Polarimetric and electrical characteristics of a lightning ring in a supercell storm. Mon. Wea. Rev., 138, 2405-2425.

Picca, J. C., and A. V. Ryzhkov, 2012: A dual-wavelength polarimetric analysis of the 16 May 2010 Oklahoma City extreme hailstorm. Mon. Wea. Rev., 140, 13851403.

, M. R. Kumjian, and A. V. Ryzhkov, 2010: ZDR columns as a predictive tool for hail growth and storm evolution. Preprints, 25th Conf. on Severe Local Storms, Denver, CO, Amer. Meteor. Soc., 11.3. [Available online at ams.confex.com/ams/pdfpapers/ 175750.pdf.]

Rasmussen, R. M., and A. J. Heymsfield, 1987: Melting and shedding of graupel and hail. Part I: Model physics. $J$. Atmos. Sci. 44, 2754-2763.

Romine, G. S., D. W. Burgess, and R. B. Wilhelmson, 2008: A dual-polarization-radar-based assessment of the 8 May 2003 Oklahoma City area tornadic supercell. Mon. Wea. Rev., 136, 2849-2870.

Rowe, A. K., S. A. Rutledge, and T. J. Lang, 2011: Investigation of microphysical processes occurring in isolated convection during NAME. Mon. Wea. Rev., 139, 424-443.

Ryzhkov, A. V., and D. S. Zrnić, 1998: Discrimination between rain and snow with a polarimetric radar. $J$. Appl. Meteor., 37, 1228-1240.

, and B. A. Gordon, 1998: Polarimetric method for ice water content determination. J. Appl. Meteor., 37, 125-134.

, D. Burgess, D. Zrnić, T. Smith, and S. Giangrande, 2002: Polarimetric analysis of a 3 May 1999 tornado. Preprints, 22nd Conf. on Severe Local Storms, Hyannis, MA, Amer. Meteor. Soc., 14.2. [Available online at ams.confex.com/ams/pdfpapers/47348.pdf.]

T. J. Schuur, D. W. Burgess, P. L. Heinselman, S. E. Giangrande, and D. S. Zrnić, 2005a: The Joint
Polarization Experiment: Polarimetric rainfall measurements and hydrometeor classification. Bull. Amer. Meteor. Soc., 86, 809-824. and D. S. Zrnić, 2005b: Polarimetric tornado detection. J. Appl. Meteor., 44, 557-570. , S. Ganson, A. Khain, M. Pinsky, and A. Pokrovsky, 2009: Polarimetric characteristics of melting hail at $S$ and $\mathrm{C}$ bands. Preprints, 34th Conf. on Radar Meteorology, Williamsburg, VA, Amer. Meteor. Soc., 4A.6. [Available online at ams.confex.com/ams/ pdfpapers/155571.pdf.]

, M. R. Kumjian, S. M. Ganson, and A. P. Khain, 2013a: Polarimetric radar characteristics of melting hail. Part I: Theoretical simulations using spectral microphysical modeling. J. Appl. Meteor. Climatol., in press.

, and P. Zhang, 2013b: Polarimetric radar characteristics of melting hail. Part II: Practical implications. J. Appl. Meteor. Climatol., in press.

Scharfenberg, K. A., D. J. Miller, T. J. Schuur, P. T. Schlatter, S. E. Giangrande, V. M. Melnikov, D. W. Burgess, D. L. Andra, M. P. Foster, and J. M. Krause, 2005: The Joint Polarization Experiment: Polarimetric radar in forecasting and warning decision making. Wea. Forecasting, 20, 775-788.

Schlatter, P. T., 2003: Polarimetric radar and in situ measurements of a non-tornadic supercell. M.S. Thesis, School of Meteorology, University of Oklahoma, $97 \mathrm{pp}$.

Schneebeli, M., N. Dawes, M. Lehning, and A. Berne, 2013: High-resolution vertical profiles of X-band polarimetric radar observables during snowfall in the Swiss Alps. J. Appl. Meteor., 52, 378-394.

Schultz, C. J., and Coauthors, 2012a: Dual-polarization tornadic debris signatures Part I: Examples and utility in an operational setting. Electronic J. Operational Meteor., 13 (9), 120-137.

, and Coauthors, 2012b: Dual-polarization tornadic debris signatures Part II: Comparisons and caveats. Electronic J. Operational Meteor., 13 (10), 138-150.

Schuur, T. J., H. S. Park, A. V. Ryzhkov, and H. D. Reeves, 2012: Classification of precipitation types during transitional winter weather using the RUC model and polarimetric radar retrievals. J. Appl. Meteor. Climatol., 51, 763-779.

Smith, P. L., D. J. Musil, A. G. Detwiler, and R. Ramachandran, 1999: Observations of mixed phase precipitation within a CaPE thunderstorm. J. Appl. Meteor., 38, 145-155.

Snyder, J. C., H. B. Bluestein, G. Zhang, and S. J. Frasier, 2010: Attenuation correction and hydrometeor classification of high-resolution, X-band, dualpolarized mobile radar measurements in severe convective storms. J. Atmos. Oceanic Technol., 27, 1979-2001. 
V. Venkatesh, and S. J. Frasier, 2013: Observations of polarimetric signatures in supercells by an X-band mobile Doppler radar. Mon. Wea. Rev., 141, 3-29.

Straka, J., and D. S. Zrnić, 1993: An algorithm to deduce hydrometeor types and contents from multiparameter radar data. Preprints, 26th Conf. on Radar Meteorology, Norman, OK, Amer. Meteor. Soc., 513516.

, and A. V. Ryzhkov, 2000: Bulk hydrometeor classification and quantification using polarimetric radar data: Synthesis of relations. J. Appl. Meteor., 39, 1341-1372.

Tanamachi, R. L., H. B. Bluestein, J. B. Houser, S. J. Frasier, and K. M. Hardwick, 2012: Mobile, X-band, polarimetric Doppler radar observations of the 4 May 2007 Greensburg, Kansas, tornadic supercell. Mon. Wea. Rev., 140, 2103-2125.

Thompson, E. J., S. A. Rutledge, B. Dolan, V. Chandrasekar, and B. L. Cheong, 2014: Development of a polarimetric radar hydrometeor classification algorithm for winter precipitation. J. Atmos. Oceanic Technol., conditionally accepted.

Trömel, S., M. R. Kumjian, A. V. Ryzhkov, C. Simmer, and M. Diederich, 2013: Backscatter differential phaseEstimation and variability. J. Appl. Meteor. Climatol., 52, 2529-2548.

Tuttle, J. D., V. N. Bringi, H. D. Orville, and F. J. Kopp, 1989: Multiparameter radar study of a microburst: Comparison with model results. J. Atmos. Sci., 46, 601-620.

Vivekanandan, J., D. S. Zrnić, S. Ellis, D. Oye, A. V. Ryzhkov, and J. M. Straka, 1999: Cloud microphysics retrieval using S-band dual-polarization radar measurements. Bull. Amer. Meteor. Soc., 80, 381-388.

Wakimoto, R. M., and V. N. Bringi, 1988: Dualpolarization observations of microbursts associated with intense convection: The 20 July storm during the MIST project. Mon. Wea. Rev., 116, 1521-1539.

Warning Decision Training Branch, 2013: Tornado warning guidance 2013: Quick reference guide. NOAA/NWS Warning Decision Training Branch, Norman, OK. 10 pp. [Available online at: www.wdtb.noaa.gov/courses/ awoc/ICSvr6/TWG2013/TWG2013-referencesheets.pdf.]

Wolde, M., and G. Vali, 2001: Polarimetric signatures from ice crystals observed at $95 \mathrm{GHz}$ in winter clouds, part II: Frequencies of occurrence. J. Atmos. Sci., 58, 842849.

Yu, T.-Y., R. R. Rondinel, and R. D. Palmer, 2009: Investigation of non-Gaussian Doppler spectra observed by weather radar in a tornadic supercell $J$. Atmos. Oceanic Technol., 26, 444-461.

Zrnić, D. S., and A. V. Ryzhkov, 1999: Polarimetry for weather surveillance radars. Bull. Amer. Meteor. Soc., 80, 389-406.

, N. Balakrishnan, C. L. Ziegler, V. N. Bringi, K. Aydin, and T. Matejka, 1993: Polarimetric signatures in the stratiform region of a mesoscale convective system. J. Appl. Meteor., 32, 678-693.

V. M. Melnikov, and A. V. Ryzhkov, 2006: Correlation coefficients between horizontally and vertically polarized returns from ground clutter. $J$. Atmos. Oceanic Technol., 23, 381-394. 